\title{
Deuterated nucleotides as chemical probes of RNA structure: a detailed protocol for the enzymatic synthesis of a complete set of nucleotides specifically deuterated at ribose carbons
}

\author{
Robert N. Azad ${ }^{1}$, Shakti Ingle ${ }^{1,2}$, and Thomas D. Tullius*1,3 \\ ${ }^{1}$ Department of Chemistry, Boston University, Boston, MA 02215, USA \\ ${ }^{2}$ Department of Biochemistry and Molecular Pharmacology, New York University School of Medicine, New York, NY 10016, \\ USA \\ ${ }^{3}$ Program in Bioinformatics, Boston University, Boston, MA 02215, USA \\ *Corresponding author's e-mail address: tullius@bu.edu
}

Published online: 29 May 2015 (version 1)

Cite as: Azad et al. ScienceOpen Research 2015 (DOI: 10.14293/S2199-1006.1.SOR-LIFE.ALCJCN.v1)

Reviewing status: Please note that this article is under continuous review. For the current reviewing status and the latest referee's comments please click here or scan the QR code at the end of this article.

Primary discipline: Biochemistry

Secondary discipline: Molecular biology, Biophysics

Keywords: RNA, Ribonucleotide synthesis, Hydroxyl radical cleavage, Specifically deuterated nucleotides

\begin{abstract}
We describe here a detailed protocol for the synthesis of ribonucleotides specifically deuterated at each ribose carbon atom. We synthesized 20 specifically deuterated ribonucleotides: ATP, CTP, GTP, and UTP, each of which contained one of five deuterated riboses (either $1^{\prime}-\mathrm{D}, 2^{\prime \prime}-\mathrm{D}, 3^{\prime}-\mathrm{D}, 4^{\prime}-\mathrm{D}$, or $5^{\prime}, 5^{\prime \prime}-\mathrm{D}_{2}$ ). Our synthetic approach is inspired by the pioneering work of Tolbert and Williamson, who developed a method for the convenient one-pot enzymatic synthesis of nucleotides (Tolbert, T. J. and Williamson, J. R. (1996) J. Am. Chem. Soc. 118, 7929-7940). Our protocol consists of a comprehensive list of required chemical and enzymatic reagents and equipment, detailed procedures for enzymatic assays and nucleotide synthesis, and chromatographic procedures for purification of deuterated nucleotides. As an example of the utility of specifically deuterated nucleotides, we used them to synthesize specifically deuterated sarcin/ricin loop (SRL) RNA and measured the deuterium kinetic isotope effect on hydroxyl radical cleavage of the SRL.
\end{abstract}

\section{INTRODUCTION}

Nucleoside $5^{\prime}$-triphosphates (NTPs) in which the ribose is specifically deuterated are valuable in structural and biochemical studies of nucleic acids. They can be used, for example, to reduce the complexity of NMR spectra [1] and to discern mechanistic details of nucleic acid cleavage [2].

Such studies provide information not otherwise obtainable. For example, we used specifically deuterated deoxynucleotides to probe the mechanism of DNA cleavage by the hydroxyl radical [3]. The ability to chemically synthesize specifically deuterated DNA allowed us to determine quantitatively which hydrogen atoms of deoxyribose are abstracted by the hydroxyl radical from duplex DNA. This work both elucidated the chemical and structural mechanism of a widely used chemical footprinting agent and contributed to a more detailed understanding of ionizing radiation-induced DNA damage.

Despite wide interest in the results of this work, the methods we described have seldom been used because of the difficulty of producing specifically deuterated NTPs by chemical synthesis [4]. Chemical routes to NTP synthesis require multiple steps that often are laborious and time-consuming. The consequence is that specifically deuterated nucleotides have been largely inaccessible to the structural and molecular biologists who would be most interested in using them.

A breakthrough in making specifically deuterated nucleotides more widely available came from Williamson and coworkers, who developed an enzymatic approach for the synthesis of deuterated ribonucleoside $5^{\prime}$-triphosphates from isotopically labeled glycerol or glucose [5-7]. Their scheme was able to produce milligram quantities of NTPs sufficient for preparing RNA by in vitro transcription for use in NMR spectroscopy. They showed that the enzymes did not have to be highly purified to be effective, which significantly reduced the effort and cost of NTP synthesis. Their synthesis is convenient, as NTPs are produced in a "one-pot" reaction that involves multiple enzymes. Williamson and coworkers used this approach to produce NTPs with multiply deuterated ribose residues, because they used commercially available uniformly deuterated glucose or glycerol in their synthetic protocols [6, 7].

While multiply deuterated NTPs are useful for NMR experiments, our earlier work [3] and the work of others [2] showed that selective deuteration at a specific deoxyribose carbon 
atom allows for the measurement of a deuterium kinetic isotope effect on hydrogen atom abstraction by a chemical probe of DNA structure. This experiment provides a chemical probe analysis of nucleic acid structure at single-atom resolution.

We describe here a comprehensive protocol, based on Williamson's pioneering work [6, 7], for the one-pot enzymatic synthesis and purification of milligram quantities of specifically deuterated adenosine $5^{\prime}$-triphosphate (ATP), guanosine $5^{\prime}$-triphosphate (GTP), uracil $5^{\prime}$-triphosphate (UTP), and cytidine $5^{\prime}$-triphosphate (CTP), for use in chemical probe experiments on RNA structure. Our protocol is designed to produce a series of NTPs each of which has deuterium incorporated at only one of the five carbon atoms of ribose, because our starting material is commercially available specifically deuterated ribose. We therefore are able to synthesize the complete set of 20 specifically deuterated ribonucleoside triphosphates, in which each ribonucleotide (ATP, UTP, CTP, or GTP) contains one of five deuterated riboses (either $1^{\prime}$-D, $2^{\prime \prime}$-D, $3^{\prime}$-D , 4'-D, or $5^{\prime}, 5^{\prime \prime}-\mathrm{D}_{2}$; see Figure $1 \mathrm{~A}$ for ribose hydrogen numbering scheme). Reactions are complete in a few hours. Reaction progress is readily monitored by high-performance
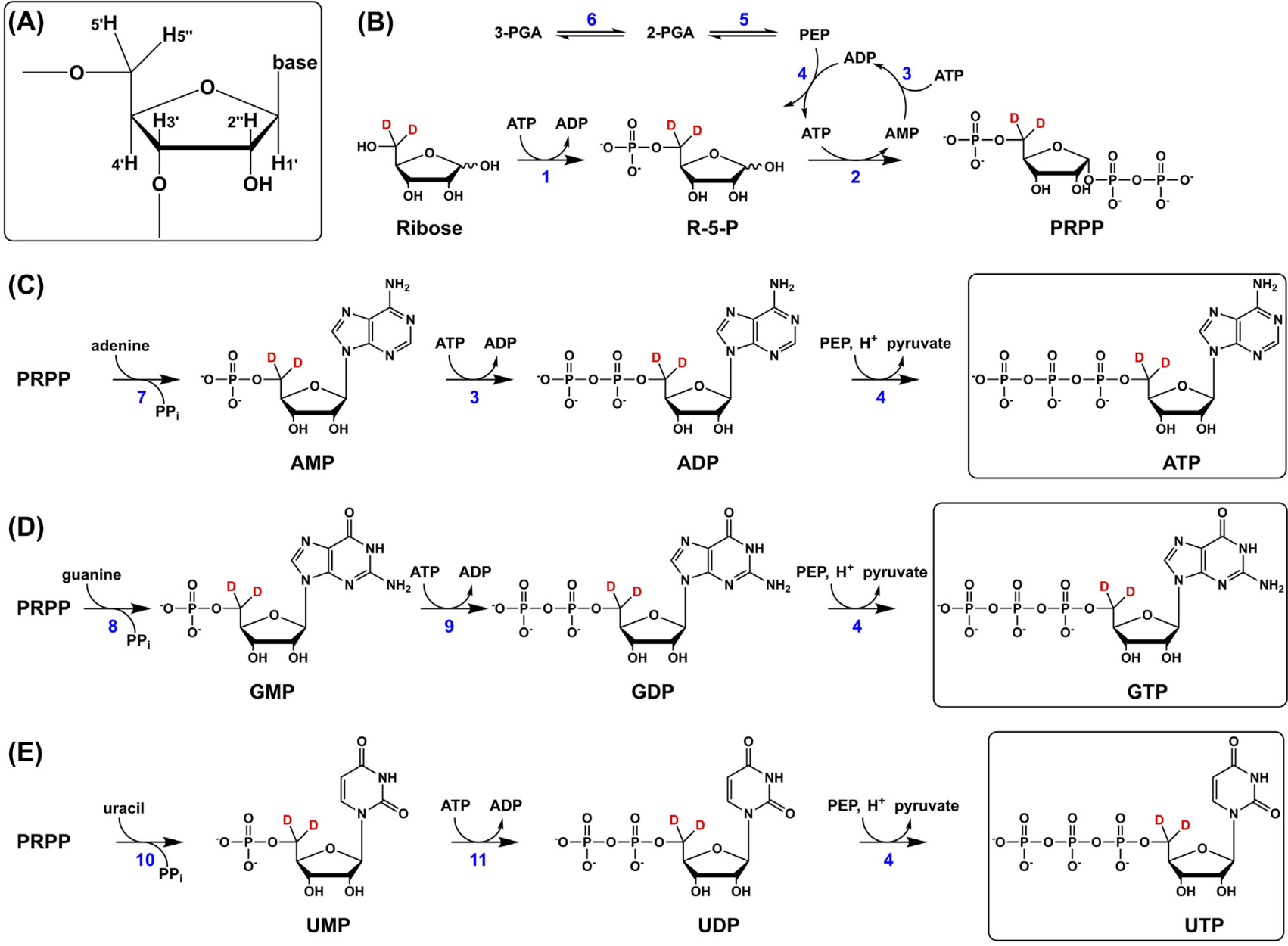

(F)

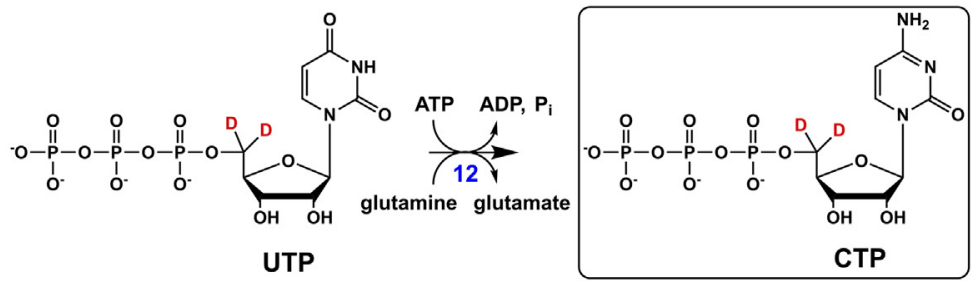

Figure 1. (A) Numbering convention for ribose hydrogens. (B) Formation of $\left[5^{\prime}, 5^{\prime \prime}-{ }_{-}{ }^{2} \mathrm{H}\right] \mathrm{PRPP}$ from labeled D-ribose. (C-E) Synthesis of 5 '-dideuterated ATP, GTP, and UTP from PRPP. (F) Conversion of 5'-dideuterated UTP to $5^{\prime}$-dideuterated CTP. Enzymes are (1) ribokinase, (2) PRPP synthetase, (3) myokinase, (4) PK, (5) enolase, (6) 3-phosphoglycerate mutase, (7) APRT, (8) XGPRT, (9) guanylate kinase, (10) UPRT, (11) NMPK, and (12) CTPS. Deuterium is colored red. This scheme adapted from Figure 3 in Tolbert et al. [7]. 
liquid chromatography (HPLC). NTPs synthesized using this protocol are greater than $98 \%$ isotopically pure at the site of deuterium substitution. A key advance that we detail in our protocol is the development of highly effective chromatographic purification of deuterated NTPs. We demonstrate that the purified deuterated NTPs are suitable for synthesis of RNA via in vitro transcription.

As a demonstration of the utility of specifically deuterated NTPs for RNA structural biology, we recently used this synthesis protocol to produce specifically deuterated NTPs for hydroxyl radical cleavage analysis of RNA structure [8]. By measuring the deuterium kinetic isotope effect on cleavage of RNA containing deuterated ribose, we quantified the reactivity of individual RNA hydrogen atoms, thereby increasing the resolution of the chemical probe experiment to the level of a single atom. We describe here in detail how to implement this experiment using specifically deuterated nucleotides.

\section{Enzymatic synthesis of NTPs}

To illustrate the synthetic scheme, in Figure 1 we show the synthesis of all four NTPs specifically deuterated at the $5^{\prime}$ carbon of ribose. Deuteration at other ribose carbons is achieved by substitution of the appropriate specifically labeled ribose in the first step of the synthesis.

The synthetic routes for generating ATP, GTP, and UTP, which adhere closely to Williamson's schemes $[6,7]$, make use of a common intermediate, 5-phospho-D-ribosyl $\alpha$-1-pyrophosphate (PRPP). In the first step, a specifically deuterated ribose (in Figure 1, D- $\left[5^{\prime}, 5^{\prime \prime}-{ }_{-}^{2} \mathrm{H}\right]$ ribose is used) is phosphorylated by ribokinase using ATP as cofactor to produce ribose-5phosphate (R-5-P; Figure 1B). Next, R-5-P is pyrophosphorylated in a reaction catalyzed by PRPP synthetase to afford PRPP. The ATP consumed in the synthetase reaction is regenerated via an enzyme system consisting of pyruvate kinase (PK) and myokinase driven by phosphoenolpyruvate (PEP). PEP is generated from excess 3-phosphoglyceric acid (3-PGA) by the enzymes phosphoglycerate mutase and enolase.

The next step after the production of PRPP is the formation of a nucleoside monophosphate, which is achieved by adding the appropriate base (adenine, guanine, or uracil) and corresponding phosphoribosyltransferase enzyme (Figure 1C-E). For example, to synthesize adenosine monophosphate from PRPP, adenine and adenine phosphoribosyltransferase (APRT) are added to the reaction mixture (Figure $1 \mathrm{C}$ ). The deuterated nucleoside monophosphate then undergoes consecutive phosphorylations, to yield first the nucleoside diphosphate and finally the desired triphosphate.

The synthesis of specifically deuterated cytidine $5^{\prime}$-triphosphate (CTP) is performed separately (Figure 1F) because CTP synthetase (CTPS) requires strict control of reaction conditions [7]. CTPS catalyzes the conversion of UTP to CTP using glutamine as a source of nitrogen and ATP as cofactor. GTP is included at low concentration since its presence stimulates the activity of CTPS.

\section{Purification of deuterated NTPs}

Because we found that the commonly used boronate affinity chromatography method is not effective under all circumstances encountered in this protocol, we developed two additional purification methods. Deuterated ATP, GTP, and UTP are purified using either boronate affinity or ionexchange chromatography, and deuterated CTP is purified using ion-pair reversed-phase HPLC.

Boronate affinity chromatography makes use of the specificity of boronate toward cis-diol moieties, such as the $\mathrm{C} 3^{\prime}$ and $\mathrm{C} 2^{\prime}$ hydroxyls in ribose. Binding of a cis-diol to boronate is sensitive to temperature, so chromatography should be performed at $4^{\circ} \mathrm{C}$. The resin is activated under alkaline conditions, and bound species are eluted using water acidified with $\mathrm{CO}_{2}$. The use of a flow adapter is not recommended since the resin bed volume collapses during the elution phase and gas is released, creating large bubbles that disturb the flow of mobile phase through the column.

While boronate resin is effective in binding ribonucleoside 5 -triphosphates, it is also capable of binding other components in the reaction mixture, such as Tris, glycerol, and unreacted ribose. This also becomes an issue when the reaction does not go to completion and substantial amounts of nucleoside 5'-mono- and diphosphates are still present.

Ion-exchange chromatography, using a volatile buffer salt such as ammonium bicarbonate, is effective in the purification of NTPs. This method has the advantage of being able to separate NTPs from the corresponding mono- and diphosphate intermediates. Ion-exchange chromatography is conveniently performed at room temperature with a flow adapter. An additional advantage is that diethylaminoethane (DEAE) resin typically costs significantly less than boronate affinity resin. A linear gradient of ammonium bicarbonate buffer ( $\mathrm{pH} 9.5)$ is used to separate and elute the NTP from the resin. The final NTP product is obtained in the form of an ammonium salt. Since NTPs elute at higher salt concentrations than is typically observed in the boronate method, 2-3 rounds of lyophilization are required to remove residual salts.

A third purification method, which is primarily used for CTP, makes use of ion-pair reversed-phase HPLC on a semipreparative scale. We found that the two methods of NTP purification described above are not suitable for CTP since they are unable to resolve the various triphosphate species required for CTP synthesis. Substantial quantities of ATP, GTP, unreacted UTP, and ADP are present in the final CTP synthesis reaction mixture. As we developed this method, a balance had to be struck between the high resolving power of HPLC and the constraint on column capacity inherent in using an analytical-scale instrument. While CTP is well resolved from interfering species, the capacity of the column we used is about $10 \mathrm{mg}$, so multiple injections were necessary to purify a typical reaction mixture. The method can be scaled up to accommodate the entire reaction mixture in a single injection 
provided that a preparative-scale HPLC instrument is available.

HPLC provides a real-time and unambiguous readout of which fractions contain the deuterated NTP of interest so that fractions can be pooled and concentrated immediately. The mobile phase additives triethylammonium acetate (TEAA) and acetonitrile are readily removed under vacuum. The final product is obtained as a triethylammonium salt. If residual TEA interferes with a downstream process, the purified NTP can be precipitated with ethanol and sodium acetate to afford the sodium salt.

\section{Enzyme preparations}

Although some of the enzymes used in the synthesis scheme (Figure 1) are commercially available, others must be expressed in E. coli and isolated. Partial purification is sufficient for many of the enzymes [6, 7]. Most of the enzyme preparations employ classical techniques such as ammonium sulfate precipitation and ion-exchange column chromatography. While effective, these techniques can be time-consuming, especially when multiple steps are required. All of the noncommercial enzymes have now been made available via expression vectors that code for enzymes containing a polyhistidine-tag (His-tag) [9, 10]. Because His-tagged enzymes can be purified directly from a cell lysate in a single, convenient, and efficient affinity chromatography step, their use will greatly streamline the synthesis protocol.

The enzymes that we used in this protocol are listed in Table 1.

\section{Enzymatic activity assays}

The activities of purified iPGM, RK, APRT, and PRPPS are determined using variants of a continuous spectrophotometric assay that monitors the absorbance decrease at $340 \mathrm{~nm}$ as $\beta$-NADH is oxidized to $\beta$-NAD $[9,15]$.

For example, in the activity assay for iPGM (Figure 2), production of 2-phosphoglyceric acid (2-PGA) from 3-PGA is coupled to the oxidation of $\beta$-NADH via the actions of enolase, $\mathrm{PK}$, and LDH [16]. Monitoring the decrease in absorbance at $340 \mathrm{~nm}$ over time yields the activity of iPGM, where one unit is defined as the amount of enzyme required to convert $1.0 \mu \mathrm{mol}$ of 3-PGA per minute in the presence of $1.3 \mathrm{mM}$ 2,3-diphosphoglycerate at $\mathrm{pH} 7.6$ at $25^{\circ} \mathrm{C}$.

The activity expressed in units per $\mathrm{mL}$ can be calculated using Equation (1):

$$
\operatorname{Activity}(\mathrm{U} / \mathrm{mL})=\frac{\left(-\Delta A_{340}\right) \times\left(V_{\mathrm{tot}}\right) \times D}{(\Delta t) \times(6.22) \times\left(V_{\mathrm{enz}}\right) \times N}
$$

where $\Delta A_{340}$ is the change in absorbance corresponding to the maximum linear rate of the reaction, $V_{\text {tot }}$ is the total volume (in $\mathrm{mL}$ ) of the reaction mixture, $D$ is the dilution factor of the enzyme solution, $\Delta t$ is the time ( $\mathrm{min}$ ) corresponding to the maximum linear rate of the reaction, 6.22 is the millimolar extinction coefficient of $\beta$-NADH at $340 \mathrm{~nm}, V_{\mathrm{enz}}$ is the volume (in $\mathrm{mL}$ ) of enzyme solution added to the reaction mixture, and $N$ is a stoichiometric coefficient equal to either 1 or 2 in our assays [11].

Ribokinase activity is determined as described by Gross et al. [11] using the enzymes PK and LDH (Figure 3A) [7, 9]. In the purification of ribokinase, other enzymes that oxidize $\beta$-NADH may also be present and thus interfere with the assay. As a consequence, the final purified ribokinase solution is assayed with and without added D-ribose to determine the baseline rate of reaction.

The activity of PRPPS is assayed using the protocol developed by Arthur et al. [9], in which the formation of PRPP from ATP and ribose-5-phosphate is coupled to the oxidation of $\beta$-NADH via the actions of myokinase, $\mathrm{PK}$, and LDH (Figure 3B).

APRT activity is assayed [9] by using the enzyme to produce adenosine monophosphate (AMP) from PRPP and adenine (see Figure 1C). The AMP then enters the cycle shown at the bottom right of Figure $3 \mathrm{~B}$, ultimately resulting in $\beta$-NADH oxidation.

The activity of uracil phosphoribosyltransferase (UPRT) is confirmed by observing the formation of UMP from uracil

Table 1. Enzymes used for NTP synthesis.

\begin{tabular}{|c|c|c|c|c|}
\hline \# & Name & Abbreviations & Native enzyme & His-tagged enzyme \\
\hline 1 & Ribokinase & RK & {$[7,11]$} & [9] \\
\hline 2 & PRPP synthetase & PRPPS & {$[7,11,12]$} & [9] \\
\hline 3 & Myokinase & MK & $\mathrm{CA}$ & \\
\hline 4 & Pyruvate kinase & PK & CA & \\
\hline 5 & Enolase & - & $\mathrm{CA}$ & \\
\hline 6 & 3-Phosphoglycerate mutase (cofactor-independent) & iPGM & {$[13]$} & {$[10]$} \\
\hline 7 & Adenine phosphoribosyltransferase & APRT & [7] & {$[9]$} \\
\hline 8 & Xanthine-guanine phosphoribosyltransferase & XGPRT & [7] & [9] \\
\hline 9 & Guanylate kinase & GK & CA & \\
\hline 10 & Uracil phosphoribosyltransferase & UPRT & {$[6]$} & [9] \\
\hline 11 & Nucleoside monophosphate kinase & NMPK & $\mathrm{CA}$ & \\
\hline 12 & CTP synthetase & CTPS & {$[7,14]$} & [9] \\
\hline
\end{tabular}

Note: CA, enzyme is commercially available. 


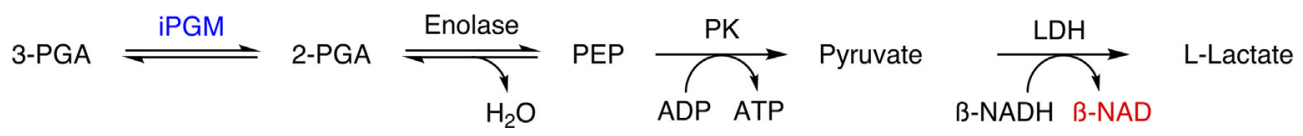

Figure 2. Scheme for assaying the enzymatic activity of phosphoglycerate mutase (iPGM) [15].
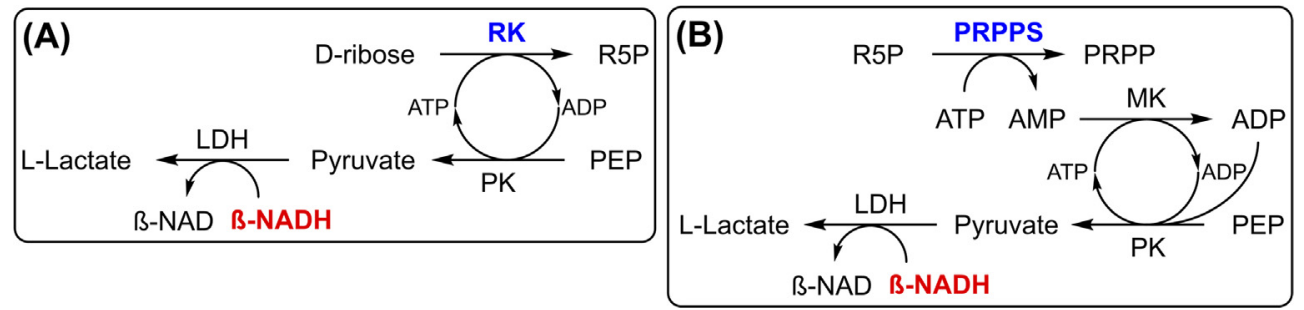

Figure 3. Schemes for assaying the enzymatic activities of (A) ribokinase and (B) PRPP synthetase [9].

and PRPP under conditions similar to those required for the synthesis of UTP (Figure 1E). After incubating the reaction mixture for a short time at room temperature, an aliquot is analyzed by HPLC for the presence of UMP. We found that the literature assay based on UV spectrophotometry [9] is not sufficiently sensitive for our purpose due to the large degree of spectral overlap between uracil and UMP.

To assay the activity of CTPS, conversion of UTP to CTP (Figure 1F) is monitored directly by HPLC at fixed time intervals. The reaction is set up on a 1-mL scale and uses standard (nondeuterated) UTP. For convenience, the reaction is set up in an HPLC vial which is placed in an autosampler at room temperature, and aliquots are injected directly into the HPLC system in an automated batch sequence.

To estimate the activity of xanthine-guanine phosphoribosyltransferase (XGPRT), the enzyme is used to synthesize GMP from PRPP in a small-scale version of the synthesis reaction that is shown in Figure 1D [7]. GMP production is monitored by HPLC.

\section{Deuterated NTPs used in the synthesis of RNA via in vitro transcription: analysis of RNA structure by hydroxyl radical cleavage}

We demonstrate the suitability of deuterated ATP for the in vitro transcription of RNA by synthesis of the sarcin/ricin loop (SRL) RNA molecule. The SRL is a short (29 nt), biologically active RNA that is part of the 50S ribosomal RNA molecule [17-19]. The manageable size and numerous structural features of the SRL make it an attractive molecule to study using cleavage by the hydroxyl radical [8]. SRL RNA is synthesized using a commercially available in vitro T7 polymerase transcription kit in the presence of $\left[5^{\prime}, 5^{\prime \prime}-{ }^{2} \mathrm{H}\right]$ ATP to yield SRL RNA containing deuterium at the $\mathrm{C}^{\prime}$ position of all adenine residues. The hydroxyl radical cleavage pattern of deuterated SRL RNA is compared to the cleavage pattern obtained from standard (nondeuterated) SRL RNA. The analysis reveals a substantial reduction in cleavage only at nucleotides that contain deuterium, indicating that RNA strand cleavage can be initiated by abstraction of a $\mathrm{C}^{\prime}$ hydrogen atom from the ribose backbone.

\section{Summary of deuterated NTP synthesis}

Twenty specifically deuterated ribonucleoside $5^{\prime}$-triphosphate analogs were synthesized and used for hydroxyl radical cleavage studies of RNA. The complete set consisted of five deuterated analogs of each of the four NTPs (ATP, GTP, UTP, and CTP). The five deuterated analogs of ATP, for example, were of the form $\left[X^{-}{ }^{2} \mathrm{H}\right] \mathrm{ATP}$, where $X=1^{\prime}, 2^{\prime \prime}, 3^{\prime}, 4^{\prime}$, or $5^{\prime}, 5^{\prime \prime}$. We found that synthesis of ATP, GTP, and UTP required substantially less 3-phosphoglyceric acid (3-PGA) than did the original protocols $[6,7]$. In all cases, 3-PGA was initially added to each reaction mixture and another bolus was added $5 \mathrm{~h}$ after the reaction was initiated. NTP formation was complete after two additions of 3-PGA.

The volumes of reagents and enzymes used in the NTP synthesis reactions were scaled down relative to those in the original protocols [7]. In most cases, reactions were run on a $15-\mathrm{mL}$ rather than a $50-\mathrm{mL}$ scale, and no adverse effects on yield were observed. For each deuterated NTP synthesized, the yield was determined by HPLC analysis of the crude reaction mixture compared to an appropriate NTP standard. The theoretical yield was calculated from the amount of D-ribose starting material and the molecular weight of the NTP. For example, in the synthesis of $\left[4^{\prime}-{ }^{2} \mathrm{H}\right] \mathrm{ATP}$, a total of $68 \mathrm{mg}$ was expected based on an input of $22 \mathrm{mg} \mathrm{D}-\left[4^{\prime}-{ }^{2} \mathrm{H}\right]$ ribose. The yield determined for the synthesis of $\left[4^{\prime}-{ }^{2} \mathrm{H}\right] \mathrm{ATP}$ on a $15-\mathrm{mL}$ scale was $\sim 65 \mathrm{mg}$, which corresponds to $96 \%$. The yields determined for each set of NTP analogs, along with the total reaction times (in parentheses), were:

- ATP: $85-96 \%(5-15 \mathrm{~h})$

- GTP: $61-76 \%(20-24 \mathrm{~h})$

- UTP: $54-86 \%(12-24 \mathrm{~h})$

- CTP: 95-99\% (5-10 h) 
When boronate affinity chromatography was employed for purification, substantial amounts of the diphosphate product (and to a lesser extent the monophosphate product) co-eluted with the target NTP. For example, all GTP synthesis reactions contained 10-20\% GDP relative to GTP. We found, though, that synthesis of RNA by in vitro transcription using purified deuterated GTP was successful despite the presence of large amounts of GDP, indicating a fair degree of tolerance of T7 polymerase for nucleoside 5'-monophosphate and $5^{\prime}$-diphosphate impurities present in NTP stock solutions.

\section{REAGENTS}

\section{Bacterial strains and plasmids for producing enzymes}

- Inducible E. coli strains for preparation of RK, PRPPS, APRT, and XGPRT. We obtained these strains $[6,7]$ as generous gifts from $\mathrm{Dr}$ James Williamson (The Scripps Research Institute, La Jolla, CA).

- Inducible E. coli strain for preparation of iPGM. We obtained this strain as a generous gift from Dr Mark J. Jedrzejas (Children's Hospital Oakland Research Institute, Oakland, CA).

- Plasmid DNA constructs encoding for His-tagged UPRT and CTPS. We obtained these plasmids as generous gifts from Dr James Williamson (The Scripps Research Institute, La Jolla, CA).

- Plasmid DNA construct encoding for His-tagged iPGM. We obtained this plasmid (pET21a) as a generous gift from Dr Clotilde Carlow (New England Biolabs, Ipswich MA).

[Note: His-tagged versions of all of the noncommercially available enzymes that are needed for this protocol have now been produced (RK, APRT, UPRT, XGPRT, CTPS, PRPPS [9]; iPGM [10]). We recommend that an interested user obtains inducible strains to express these His-tagged enzymes, which will greatly simplify isolation and purification of the enzymes.]

\section{Commercially available enzymes}

- Myokinase from rabbit muscle (MK; Sigma-Aldrich, cat. no. M3003)

- Pyruvate kinase from rabbit muscle (PK; SigmaAldrich, cat. no. P7768)

- Enolase from baker's yeast (Sigma-Aldrich, cat. no. E6126)

- Guanylate kinase (GK; Sigma-Aldrich, cat. no. G9385)

- Nucleoside monophosphate kinase (NMPK; Roche Applied Science, cat. no. 10107948001)

- D-Lactic dehydrogenase (LDH; Sigma-Aldrich, cat. no. L3888)

- Inorganic pyrophosphatase (New England Biolabs, cat. No. M2403S)

- Lysozyme (Sigma-Aldrich, cat. no. L6876)

- Antarctic phosphatase (AP; New England Biolabs, cat. no. M0289S)

- T4 polynucleotide kinase (T4 PNK; New England Biolabs, cat. no. M0201S)

\section{Reagents for enzyme preparation}

- One Shot BL21(DE3) Chemically Competent E. coli cells (Life Technologies, cat. no. C600003)

- LB broth (Miller; Sigma-Aldrich, cat. no. L3022)

- Ampicillin sodium salt (Sigma-Aldrich, cat. no. A0166)

- 3-Indoleacrylic acid (Sigma-Aldrich, cat. no. I2273)

- 2-Mercaptoethanol (BME; Sigma-Aldrich, cat. no. M3148)

- Dithiothreitol (DTT; Sigma-Aldrich, cat. no. D0632)

- Isopropyl $\beta$-D-1-thiogalactopyranoside (IPTG; SigmaAldrich, cat. no. I6758)

- Streptomycin sulfate salt (Sigma-Aldrich, cat. no. S6501)

- TALON Metal Affinity Resin (Clontech, cat. no. 635502)

- Phenylmethylsulfonyl fluoride (PMSF; Sigma-Aldrich, cat. no. P7626)

- Precision Plus Protein Dual Color Standards (Bio-Rad, cat. no. 161-0374)

\section{Reagents for enzyme activity assays, NTP synthesis, and NTP purification}

- Triethanolamine (TEA; Sigma-Aldrich, cat. no. T-1502)

- Acetic acid (glacial; Sigma-Aldrich, cat. no. 320099)

- 5-Phospho-D-ribose 1-diphosphate pentasodium salt (PRPP; Sigma-Aldrich, cat. no. P8296)

- D-(-)-3-Phosphoglyceric acid disodium salt (3-PGA; Sigma-Aldrich, cat. no. 79472)

- Adenosine 5'-diphosphate sodium salt (ADP; SigmaAldrich, cat. no A2754)

- Adenosine 5'-triphosphate disodium salt hydrate (ATP; Sigma-Aldrich, cat. no. A6419)

- Guanosine 5'-triphosphate sodium salt hydrate (GTP; Sigma-Aldrich, cat. no. G8877)

- L-Glutamine (Sigma-Aldrich, cat. no. G3126)

- 2,3-Diphospho-D-glyceric acid penta(cyclohexylammonium) salt (DPGA; Sigma-Aldrich, cat. no. D9134)

- $\quad \beta$-Nicotinamide adenine dinucleotide, reduced dipotassium salt ( $\beta$-NADH; Sigma-Aldrich, cat. no. N4505)

- Phospho(enol)pyruvic acid trisodium salt hydrate (PEP; Sigma-Aldrich, cat. no. P7002)

- D-Ribose 5-phosphate disodium salt hydrate (R-5-P; Sigma-Aldrich, cat. no. R7750)

- D-Ribose (Sigma-Aldrich, cat. no. R7500)

- Adenine hydrochloride hydrate (Sigma-Aldrich, cat. no. A8751)

- Guanine hydrochloride (Sigma-Aldrich, cat. no. 51031)

- Uracil (Sigma-Aldrich, cat. no. U0750)

- Cytosine (Sigma-Aldrich, cat. no. C3506)

- Magnesium sulfate $\left(\mathrm{MgSO}_{4} ;\right.$ Sigma-Aldrich, cat. no. M2643)

- Manganese(II) chloride $\left(\mathrm{MnCl}_{2}\right.$; Sigma-Aldrich, cat. no. 450995)

- Potassium chloride (KCl; Sigma-Aldrich, cat. no. P9641)

- $\mathrm{D}-\left[X-{ }^{2} \mathrm{H}\right]$ ribose, where $X=1^{\prime}, 2^{\prime \prime}, 3^{\prime}, 4^{\prime}$, or $5^{\prime}, 5^{\prime \prime}$ (Omicron Biochemicals, cat. nos. RIB-016, RIB-017, RIB-018, RIB-019, RIB-020) 
- Sodium phosphate monobasic $\left(\mathrm{NaH}_{2} \mathrm{PO}_{4} ;\right.$ SigmaAldrich, cat. no. S3139)

- Sodium phosphate dibasic $\left(\mathrm{Na}_{2} \mathrm{HPO}_{4} ;\right.$ Sigma-Aldrich, cat. no. S3264)

- Acetonitrile (HPLC-grade; Fisher Scientific, cat. no. A9981)

- Affi-Gel boronate gel (Bio-Rad, cat. no. 153-6103)

- Toyopearl DEAE-650M anion-exchange resin (Tosoh Bioscience, cat. no. 07473)

\section{Reagents for RNA synthesis and analysis, and hydroxyl radical cleavage}

- MEGAShortscript T7 Transcription Kit (Life Technologies, cat. no. AM1354)

- $\left[\gamma_{-}{ }^{32} \mathrm{P}\right] \mathrm{ATP}(3000 \mathrm{Ci} / \mathrm{mmol}, 10 \mathrm{mCi} / \mathrm{ml}$; Perkin-Elmer, cat. no. BLU002A250UC)

- Ammonium iron(II) sulfate hexahydrate $\left(\left[\left(\mathrm{NH}_{4}\right)_{2} \mathrm{Fe}\right.\right.$ $\left(\mathrm{SO}_{4}\right)_{2} 6 \mathrm{H}_{2} \mathrm{O}$ ]; Sigma-Aldrich, cat. no. 203505)

- EDTA disodium solution (0.5 M; Life Technologies, cat. no. 15575-020)

- (+)-Sodium L-ascorbate (Sigma-Aldrich, cat. no. A7631)

- Hydrogen peroxide $\left(\mathrm{H}_{2} \mathrm{O}_{2}, 30 \%\right.$; Sigma-Aldrich, cat. no. 95321)

- Thiourea (Fisher, cat. no. T101-100) CAUTION: Potential carcinogen. May cause irritation to the eyes, skin and respiratory tract. Wear gloves, lab coat and safety goggles when handling thiourea solutions.

- Milli-Q purified water or equivalent, autoclaved. Purified water is indicated in this protocol by $\mathrm{dH} 2 \mathrm{O}$. CRITICAL: The quality of water used in the preparation of reagents and buffers is very important. Organic contaminants in the water can interfere with the hydroxyl radical cleavage reaction, as can contaminating metal ions (such as iron or copper).

- Sodium acetate, 3 M solution, pH 5.5 (Life Technologies, cat. no. AM9740)

- Ethanol (100 and $70 \% \mathrm{vol} / \mathrm{vol}$ ) chilled to $-20^{\circ} \mathrm{C}$

- $\quad N, N^{\prime}$-tetramethylethylenediamine (TEMED; Sigma, cat. no. T9281) CAUTION: Wear gloves, lab coat, and safety goggles when handling TEMED solutions.

- Ammonium persulfate (APS; Fisher, cat. no. BP 179)

- Urea (Sigma-Aldrich, cat. no. U5378)

- Sigmacote (Sigma-Aldrich, cat. no. SL-2)

- Acrylamide/bis solution, 40\%, 19:1 (Bio-Rad, cat no. 161-0144)

- TBE buffer (10×; Life Technologies, cat. no. AM9863)

\section{EQUIPMENT}

- Pipettors, 1-10, 2-20, 20-200, and 200-1,000 $\mu \mathrm{l}$ (models P10, P20, P200, and P1000, respectively; Gilson), and corresponding tips

- Gel-loading tips, $0.4 \mathrm{~mm}$ (Rainin, cat. no. GT-250-4)

- Microcentrifuge (e.g., Eppendorf model no. 5415 C)

- Ultracentrifuge, rotor, canisters, and 0.5-L plastic bottles

- HPLC system (e.g., Dionex, Ultimate 3000) equipped with an autosampler, $0.1-100 \mu \mathrm{L}$ syringe, 4 solvent channels, temperature-controlled column compartment, UV/Visible multichannel wavelength detector, and an automated fraction collector (e.g., Dionex, AFC-3000)

- Hypersil GOLD C18 preparative HPLC column $(250 \times$ $10 \mathrm{~mm}$; Thermo Scientific, cat. no. 25005-259070)

- DNAPac PA 200 analytical HPLC column $(250 \times 4 \mathrm{~mm}$; Dionex Corporation, cat. no. 063000)

- Amicon Ultra-15 centrifugal filter (10 kDa NMWL; Millipore, cat. no. UFC901024)

- NucAway spin columns (Life Technologies, cat. no. AM10070)

- Econo-Column glass chromatography column $(2.5 \times$ $20 \mathrm{~cm}$; Bio-Rad, cat. no. 737-2522)

- Flow adapter for Econo-Column (Bio-Rad, cat. no. 738-0017)

- Gradient maker (C.B.S. Scientific, cat. no. GM-500)

- Cuvette for UV-visible spectrophotometry

- 25-mL round bottom flask and stir bar

- $\mathrm{pH}$ electrode

- Medium or large inflatable balloon

- Acrodisc syringe filter $(0.2-\mu \mathrm{m}$ pore size; Pall Corporation, cat. no. 4652)

- Lyophilizer

- Vertical gel electrophoresis apparatus for running SDSpolyacrylamide gels (e.g., Mini-PROTEAN Tetra Cell; Bio-Rad Laboratories, cat. no. 165-8002)

- Vertical gel electrophoresis apparatus for running thin sequencing (denaturing) gels (e.g., model no. S3S T-Rex Aluminum Backed Sequencer; Owl Separation Systems)

- Gel dryer

- Side-arm flask and stopper, and access to laboratory vacuum or a water aspirator

- Spacer set and 30-well comb (0.33 mm thick)

- Power supply (5,000 V; e.g., PowerPac HV; Bio-Rad, cat. no. 164-5056)

- Plastic wrap

- Chromatography paper (Whatman, cat. no. 3030917)

- Typhoon Trio Phosphorimager, including storage phosphor screens, exposure cassettes, and ImageQuant software (GE Healthcare, cat. no. 63-0035-62)

- SAFA gel analysis software [20]. The software and documentation are freely available for download at http://safa.stanford.edu

\section{PROCEDURES}

Transformation of E. coli with the expression vector for an enzyme

(1) Thaw one vial of One Shot BL21(DE3) competent E. coli on ice and then add $2 \mu \mathrm{l}$ of a stock solution of the expression plasmid to the vial, mix gently, and let sit for about $20 \mathrm{~min}$ on ice. Heat-shock the bacteria for $30 \mathrm{~s}$ in a water bath set to $42^{\circ} \mathrm{C}$, add $250 \mu$ l of Super Optimal broth with catabolite repression (SOC) medium (part of the kit), and incubate at $37^{\circ} \mathrm{C}$ for $1 \mathrm{~h}$ with shaking. Spread 5 and $20 \mu \mathrm{l}$ of the transformed bacteria on separate LB agar plates (containing $100 \mu \mathrm{g} / \mathrm{mL}$ ampicillin if the plasmid encodes AmpR) and incubate overnight at $37^{\circ} \mathrm{C}$. 
(2) Use individual colonies from the plates to inoculate two 5-mL starter cultures and incubate overnight at $37^{\circ} \mathrm{C}$ with shaking.

(3) Transfer one overnight culture to $1 \mathrm{~L}$ of pre-warmed LB media containing $100 \mu \mathrm{g} / \mathrm{mL}$ ampicillin and incubate at $37^{\circ} \mathrm{C}$ with shaking.

(4) To avoid the cell transformation step in the future, prepare a cell stock from the other culture by pelleting the cells in a centrifuge, resuspending the cell pellet in $0.5 \mathrm{~mL}$ of fresh LB media, mixing with an equal volume of glycerol, and storing at $-80^{\circ} \mathrm{C}$.

\section{Preparation of His-tagged UPRT and CTPS}

(1) Incubate cells containing the appropriate expression vector for about $4 \mathrm{~h}$ with continuous shaking at $220 \mathrm{rpm}$ until the absorbance at $600 \mathrm{~nm}$ is greater than $0.6 \mathrm{AU}$.

(2) Induce expression of the enzyme by adding IPTG to a final concentration of $1 \mathrm{mM}$. Incubate an additional $4 \mathrm{~h}$ with shaking.

(3) Remove a 1-mL aliquot each hour of growth and assay for the presence of the overexpressed enzyme of interest using SDS-PAGE (UPRT, Figure 4A; CTPS, Figure 5A).

(4) Harvest cells by centrifugation at $10,000 \mathrm{~g}$ for $30 \mathrm{~min}$ at $4^{\circ} \mathrm{C}$. Gently resuspend the pellet in 25 $\mathrm{mL}$ lysis buffer (50 mM Tris-HCl (pH 7.5), $250 \mathrm{mM}$ $\mathrm{NaCl}$ ).

(5) Probe-tip sonicate cells, on ice, for three cycles of $10 \mathrm{~s}$ "on" followed by $10 \mathrm{~s}$ "off," pause for $2 \mathrm{~min}$, and complete 3 more cycles of $10 \mathrm{~s}$ "on" followed by $10 \mathrm{~s}$ "off."
(6) Pellet the cell debris by centrifugation at $30,000 \mathrm{~g}$ for $30 \mathrm{~min}$ at $4^{\circ} \mathrm{C}$. Collect the supernatant for chromatography.

(7) Pack a chromatography column in the cold room with about $3 \mathrm{~mL}$ of His-tag affinity resin and equilibrate with lysis buffer containing 10-mM imidazole.

(8) Apply the supernatant sample directly to the column and continue to wash with about five column volumes of lysis buffer containing $10-\mathrm{mM}$ imidazole.

(9) Elute bound protein with lysis buffer containing 200-mM imidazole while collecting 5-mL fractions. Analyze the fractions using SDS-PAGE (UPRT, Figure 4B; CTPS, Figure 5B) and pool those containing the enzyme of interest.

(10) Concentrate the protein solution and exchange the buffer: transfer the purified protein solution to a centrifugal filter (10 $\mathrm{kDa} \mathrm{NMWL})$ and centrifuge at $4,000 \mathrm{~g}$ in a swinging bucket rotor until about $1 \mathrm{~mL}$ remains in the upper chamber. Discard the flowthrough, add $13 \mathrm{~mL}$ cold $100-\mathrm{mM}$ potassium phosphate buffer $(\mathrm{pH} 7.4)$ to the upper chamber, and centrifuge at $4,000 \mathrm{~g}$ until about $1 \mathrm{~mL}$ remains in the upper chamber. Repeat the dilution and centrifugation steps twice more.

(11) Add an equal volume of glycerol, mix well, and store at $-20^{\circ} \mathrm{C}$ for short times ( $<4$ weeks) or $-80^{\circ} \mathrm{C}$ for longer times.

\section{UPRT enzyme activity assay}

(1) Prepare a 5-mL solution consisting of the reagents that are listed in Table 2.

(2) Aliquot $1 \mathrm{~mL}$ of the reagent mixture into each of four fresh $1.5-\mathrm{mL}$ tubes and let them sit for at least $5 \mathrm{~min}$ at room temperature.
(A)

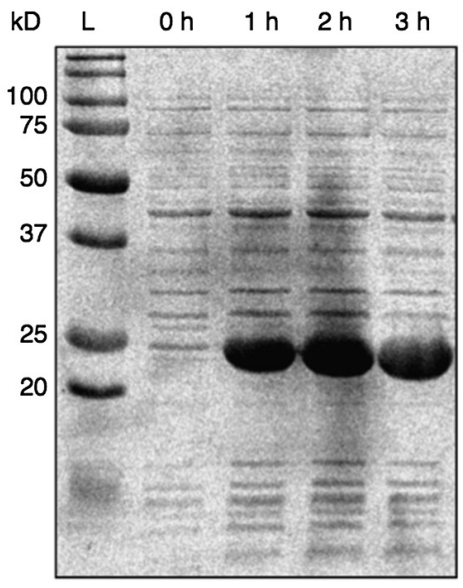

(B)

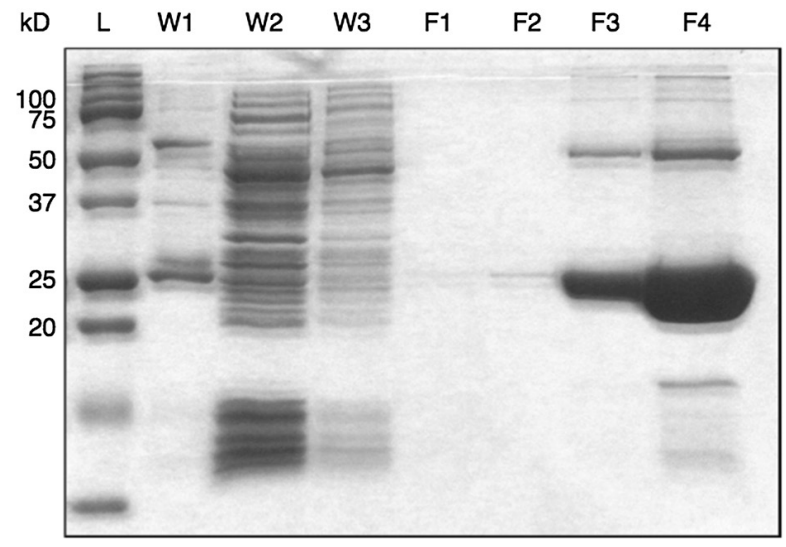

Figure 4. (A) SDS-PAGE analysis of E. coli whole cell lysates before and after the induction of UPRT expression. Lane L, protein sizestandard ladder with the molecular weight $(\mathrm{KD})$ labeled next to each band. The time after induction of protein expression is labeled above each lane. (B) SDS-PAGE analysis of fractions collected during the purification of the UPRT enzyme by His-tag affinity chromatography. Lane L, protein size-standard ladder with the molecular weight (KD) labeled next to each band. Wash fractions are labeled W1, W2, and W3; elution fractions are labeled F1, F2, F3, and F4. 
(A)

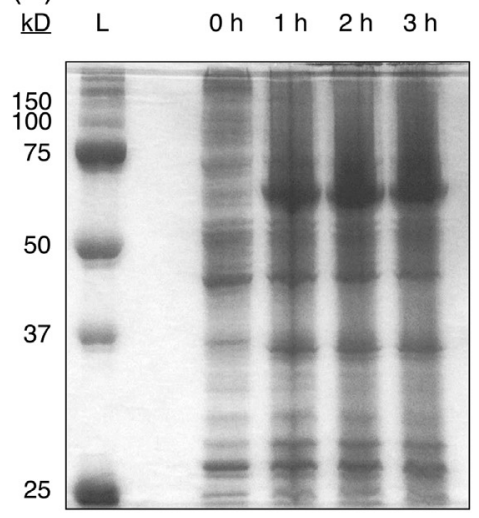

(B)

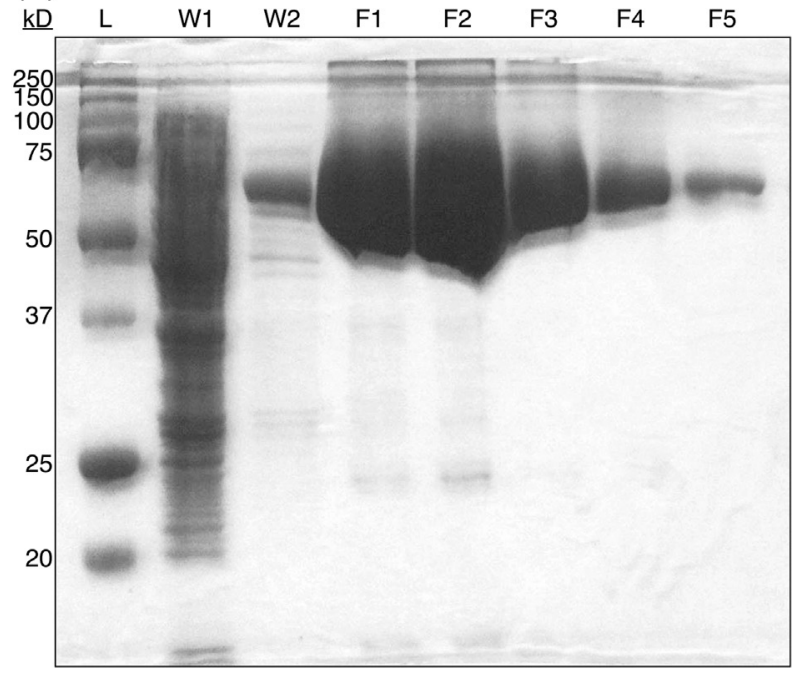

Figure 5. (A) SDS-PAGE analysis of E. coli whole cell lysates before and after the induction of CTPS expression. Lane L, protein sizestandard ladder with the molecular weight (kD) labeled next to each corresponding band. (B) SDS-PAGE analysis of fractions collected during the purification of the CTPS enzyme by affinity chromatography. Wash fractions are labeled W1 and W2; elution fractions are labeled as F1, F2, F3, F4, and F5.

Table 2. Reagents for UPRT assay.

\begin{tabular}{lc}
\hline Reagent & Final conc. (mM) \\
\hline Tris-HCl (pH 7.5) & 50 \\
Uracil & 0.1 \\
PRPP & 1.5 \\
\hline
\end{tabular}

(3) Add 0, 1, 10, and $40 \mu \mathrm{L}$ UPRT enzyme solution to each tube to initiate the reaction. Incubate the reaction mixture at room temperature for $1.5 \mathrm{~h}$.

(4) Perform an HPLC analysis (see "HPLC analysis of NTPs," below) of each sample, including the blank, to confirm the production of UMP in each reaction.

\section{CTPS enzyme activity assay}

(1) Directly in a 2-mL HPLC sample vial, prepare a 1-mL solution at room temperature consisting of the reagents that are listed in Table 3 .

(2) Add 10-40 $\mu \mathrm{L}$ CTPS enzyme solution to the vial. Incubate for $10 \mathrm{~min}$ at room temperature.

(3) Meanwhile, set up an analytical HPLC batch run (see "HPLC analysis of NTPs," below) that will perform periodic $10-\mu \mathrm{L}$ injections over a 5 -hr period.

(4) Add $0.2 \mathrm{~mL}$ of $50-\mathrm{mM}$ glutamine in water to initiate the reaction. Place the sample vial in the HPLC autosampler and start the batch run.

(5) Use the peak areas of CTP and the injection time stamps to visualize the progression of the CTPS reaction (Figure 6).
Table 3. Reagents for CTPS assay.

\begin{tabular}{lc}
\hline Reagent & Final conc. (mM) \\
\hline Tris-HCl (pH 7.8) & 50 \\
$\mathrm{MgCl}_{2}$ & 10 \\
UTP & 1.0 \\
ATP & 2.5 \\
GTP & 0.2 \\
\hline
\end{tabular}

\section{Preparation of iPGM}

(1) Incubate cells that have been transformed with the expression vector for iPGM at $37^{\circ} \mathrm{C}$ for about $8 \mathrm{~h}$ with shaking until the $A_{260}$ is $>0.7 \mathrm{AU}$

(2) Split the culture into two 0.5-L plastic bottles and chill on ice for $10 \mathrm{~min}$. Centrifuge the cell suspension at $6,000 \mathrm{~g}$ for $15 \mathrm{~min}$ at $4^{\circ} \mathrm{C}$, discard the supernatant, and resuspend the cell pellet in 15-mL cold lysis buffer (50 mM HEPES ( $\mathrm{pH} 7.4$ ), $10 \%$ sucrose (wt/vol), $1 \mathrm{mM}$ DTT). Transfer the sample to a fresh conical tube.

(3) Add $6 \mathrm{mg}$ lysozyme and $200 \mu \mathrm{L} 0.1 \mathrm{M}$ EDTA to the mixture and mix. Incubate the sample for $20 \mathrm{~min}$ at $37^{\circ} \mathrm{C}$ and then place on ice.

(4) Probe-tip sonicate, on ice, for three cycles of $10 \mathrm{~s}$ "on" followed by $10 \mathrm{~s}$ "off," pause for $2 \mathrm{~min}$, and complete three more cycles of $10 \mathrm{~s}$ "on" followed by $10 \mathrm{~s}$ "off."

(5) Centrifuge the lysate at $32,000 \mathrm{~g}$ for $1 \mathrm{~h}$ at $4^{\circ} \mathrm{C}$ and transfer the supernatant to a fresh conical tube.

(6) Add $\mathrm{MnCl}_{2}$ to a final concentration of $1.2 \mathrm{mM}$ and PMSF (stock solution in 2-propanol) to a final concentration of $100 \mu \mathrm{M}$. 

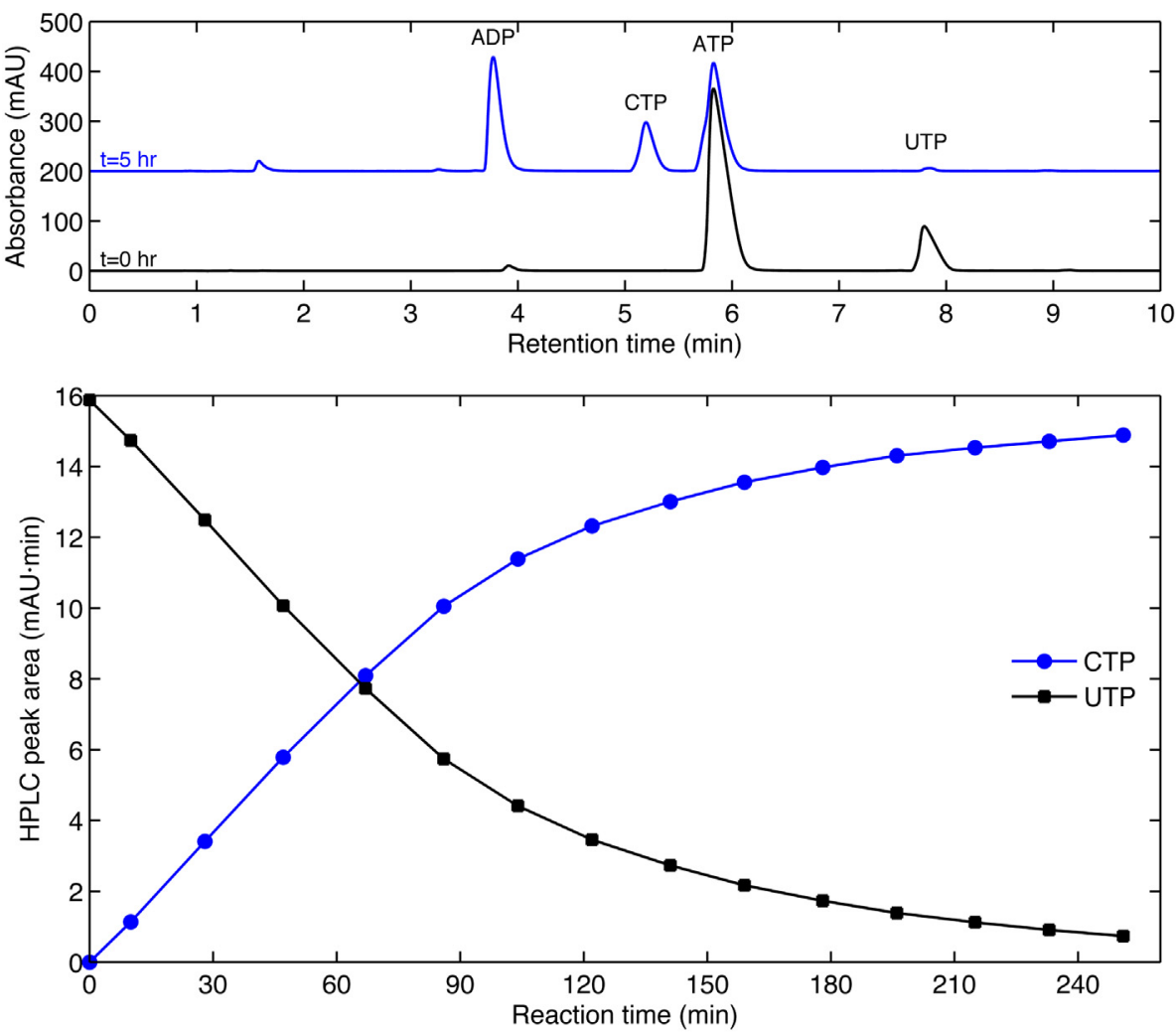

Figure 6. (A) Analytical HPLC chromatograms of the CTPS assay reaction mixture at $0 \mathrm{~h}$ (black trace) and $5 \mathrm{~h}$ (blue trace) after initiating the reaction. (B) HPLC peak area analysis of the CTPS reaction time-course. CTP, blue curve; UTP, black curve.

(7) Apply $1.6 \mathrm{~mL} \mathrm{20 \%} \mathrm{streptomycin} \mathrm{sulfate} \mathrm{solution}$ (wt/vol) and mix well. Incubate the sample for $2 \mathrm{~min}$ at $45^{\circ} \mathrm{C}$ and then place on ice. Centrifuge the solution at $30,000 \mathrm{~g}$ for $30 \mathrm{~min}$ at $4^{\circ} \mathrm{C}$ to remove the precipitate and transfer the supernatant to a fresh conical tube.

(8) Under continuous and gentle stirring, slowly add enough solid ammonium sulfate to the sample solution to achieve $50 \%$ saturation. Continue stirring while allowing the sample to sit for an additional 10-20 min to allow for full equilibration. Centrifuge the sample at $20,000 \mathrm{~g}$ for $20 \mathrm{~min}$ at $4{ }^{\circ} \mathrm{C}$ and then transfer the supernatant to a fresh conical tube. Add enough ammonium sulfate to achieve $80 \%$ saturation, allow the sample to stand an additional $10 \mathrm{~min}$, and then centrifuge again for $15 \mathrm{~min}$. Resuspend the pellet in $5 \mathrm{~mL}$ cold Buffer A (50 mM HEPES (pH 7.4), $100 \mathrm{mM}$ $\mathrm{KCl}, 1 \mathrm{mM}$ DTT, $0.1 \mathrm{mM}$ PMSF, $0.05 \mathrm{mM}$ EDTA, and $0.25 \mathrm{mM} \mathrm{MnCl}_{2}$ ).

(9) Transfer the sample solution to a dialysis sack with a 12,000 MW cutoff and dialyze against $2 \mathrm{~L}$ Buffer A at $4^{\circ} \mathrm{C}$ for $3 \mathrm{~h}$. Replace the used buffer with $2 \mathrm{~L}$ fresh Buffer A and dialyze for additional $3 \mathrm{~h}$.

(10) Mix the sample solution with an equal volume of glycerol, mix well, and store at $-80^{\circ} \mathrm{C}$.
Table 4. Reagents for iPGM assay.

\begin{tabular}{lc} 
Reagent & Final conc. (mM) \\
\hline Triethanolamine buffer $(\mathrm{pH} 7.6)$ & 79 \\
3-PGA & 6.6 \\
$\mathrm{ADP}$ & 0.7 \\
$\mathrm{DPGA}$ & 1.3 \\
$\beta$-NADH & 0.15 \\
$\mathrm{MgSO}_{4}$ & 2.5 \\
$\mathrm{KCl}$ & 99 \\
\hline
\end{tabular}

\section{iPGM enzyme activity assay}

(1) In a $15-\mathrm{mL}$ conical tube (wrapped in aluminum foil to protect from light exposure), prepare a $5 \mathrm{~mL}$ solution at room temperature containing the reagents that are listed in Table 4 .

(2) Add $66 \mathrm{U}$ D-lactic dehydrogenase, $46 \mathrm{U}$ PK, and $10 \mathrm{U}$ enolase to the reagent mixture and equilibrate at room temperature for 5-10 $\mathrm{min}$.

(3) Meanwhile, prepare a 20 -fold dilution of the iPGM enzyme solution in $80 \mathrm{mM}$ triethanolamine buffer (pH 7.6), containing $100 \mathrm{mM} \mathrm{KCl}$ and $2.5 \mathrm{mM} \mathrm{MgSO}_{4}$.

(4) Add $1.0 \mathrm{~mL}$ of the reaction mixture into a cuvette and blank the spectrophotometer at $340 \mathrm{~nm}$. 


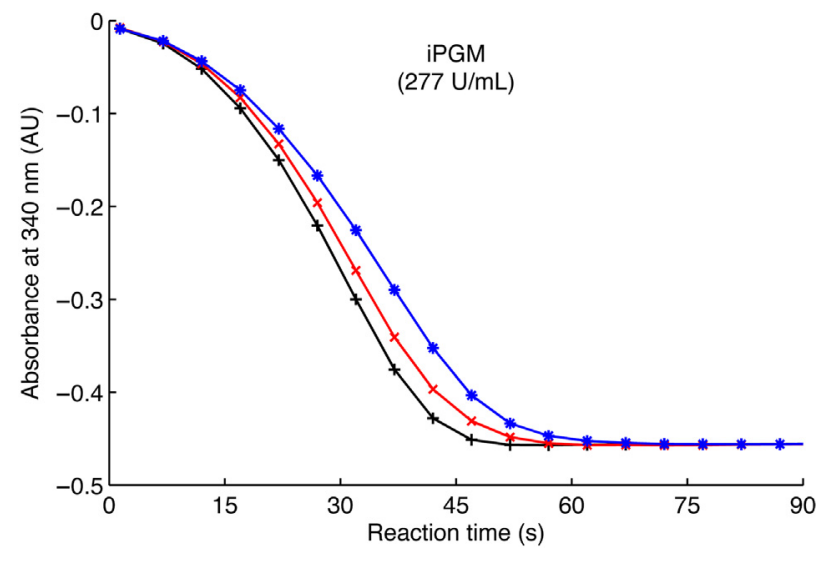

Figure 7. Enzymatic activity assay of phosphoglycerate mutase (iPGM). The activity was calculated using the maximum linear rate observed in each trace (Equation 1 ) and reported as the average of triplicate measurements. A typical activity is shown.

(5) Add $10 \mu \mathrm{L}$ of the diluted iPGM solution to the cuvette to initiate the reaction. Record the absorbance at 340 $\mathrm{nm}$ every $5 \mathrm{~s}$ for a total of $5 \mathrm{~min}$. Repeat the measurement twice with fresh reagent mixture and iPGM enzyme solution.

(6) Determine the iPGM activity, in units per mL, of each replicate measurement using Equation 1 with $N=1$. Report the final activity as an average of all replicates (Figure 7).

\section{Preparation of PRPPS}

(1) Incubate cells that have been transformed with the expression vector for PRPPS at $37^{\circ} \mathrm{C}$ for about $7 \mathrm{~h}$ with shaking

(2) Harvest the cells by centrifugation at $10,000 \mathrm{~g}$ for $30 \mathrm{~min}$ at $4^{\circ} \mathrm{C}$. Resuspend the pellet in $25-\mathrm{mL}$ cold 50-mM potassium phosphate buffer ( $\mathrm{pH} 7.5$ )

(3) Probe-tip sonicate, on ice, for three cycles of $10 \mathrm{~s}$ "on" followed by $10 \mathrm{~s}$ "off," pause for $2 \mathrm{~min}$, and complete three more cycles of $10 \mathrm{~s}$ "on" followed by $10 \mathrm{~s}$ "off."

(4) Pellet the cell debris by centrifugation at $30,000 \mathrm{~g}$ for $1 \mathrm{~h}$ at $4^{\circ} \mathrm{C}$.

(5) To the supernatant, add $2.5 \mathrm{~mL}$ of $20 \%$ streptomycin sulfate solution (wt/vol) and mix well. Incubate the sample for $2 \min$ at $45^{\circ} \mathrm{C}$ and then place on ice. Centrifuge the solution at $30,000 \mathrm{~g}$ for $30 \mathrm{~min}$ at $4^{\circ} \mathrm{C}$ to remove the precipitate. Transfer the supernatant to a fresh conical tube.

(6) Under continuous and gentle stirring, slowly add enough solid ammonium sulfate to the sample solution to achieve $35 \%$ saturation. Continue stirring while allowing the sample to sit for an additional 10-20 min to allow for full equilibration. Centrifuge the sample, discard the supernatant, and resuspend
Table 5. Reagents for PRPPS assay.

\begin{tabular}{lc}
\hline Reagent & Final conc. (mM) \\
\hline $\mathrm{K}_{2} \mathrm{HPO}_{4}$ & 100 \\
Ribose-5-phosphate & 5 \\
ATP & 3 \\
$\mathrm{PEP}$ & 0.8 \\
$\beta$-NADH & 0.2 \\
$\mathrm{MgSO}_{4}$ & 10 \\
$\mathrm{KCl}$ & 142 \\
\hline
\end{tabular}

the pellet in $25-\mathrm{mL}$ cold $50-\mathrm{mM}$ potassium phosphate buffer ( $\mathrm{pH} 7.5)$.

(7) Add $0.1 \mathrm{M}$ acetic acid dropwise under continuous stirring at $4^{\circ} \mathrm{C}$ until the $\mathrm{pH}$ reaches 4.5 . Centrifuge the sample and discard the supernatant. Resuspend the pellet in $20-\mathrm{mL}$ cold $50-\mathrm{mM}$ potassium phosphate buffer ( $\mathrm{pH} 7.5)$.

(8) Concentrate the sample and exchange the buffer using a centrifugal filter (10 kDa NMWL): centrifuge at $4,000 \mathrm{~g}$ in a swinging bucket rotor until about 1 $\mathrm{mL}$ remains in the upper chamber, add $13 \mathrm{~mL}$ cold buffer, and centrifuge again until about $1 \mathrm{~mL}$ remains in the upper chamber. Repeat twice.

(9) Collect the remaining liquid from the upper chamber and assay it for PRPPS activity.

\section{PRPPS enzyme activity assay}

(1) In $100 \mathrm{mM}$ triethanolamine buffer ( $\mathrm{pH} 7.6)$, prepare a $10 \mathrm{~mL}$ stock solution of the reagents that are listed in Table 5.

(2) Add $20 \mathrm{U}$ each of the following enzymes: D-lactic dehydrogenase, PK, and myokinase.

(3) Add a 20- $\mu \mathrm{L}$ aliquot of the PRPPS sample to initiate the reaction. Record the absorbance at $340 \mathrm{~nm}$ every $5 \mathrm{~s}$ for a total of $5 \mathrm{~min}$.

(4) Determine the PRPPS activity, in units per $\mathrm{mL}$, of each replicate measurement using Equation 1 with $N=2$. Report the final activity as an average of all replicates (Figure 8).

\section{Preparation of RK}

(1) Incubate cells that have been transformed with the expression vector for RK for $4 \mathrm{~h}$ with continuous shaking at $220 \mathrm{rpm}$ until the absorbance at $600 \mathrm{~nm}$ is greater than $0.6 \mathrm{AU}$.

(2) Add $1 \mathrm{~mL} 3$-indoleacrylic acid $(25 \mathrm{mg} / \mathrm{mL}$ in ethanol) to induce the expression of ribokinase. Incubate the culture for an additional 8-10 $\mathrm{h}$ with shaking. After every 1-2 h of growth, remove a 1 -mL aliquot and store at $4^{\circ} \mathrm{C}$. 


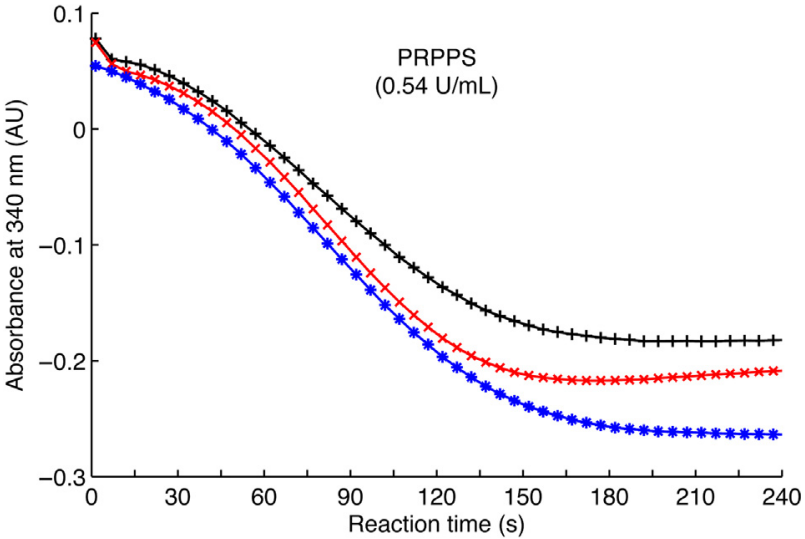

Figure 8. Enzymatic activity assay of PRPP synthetase. The activity was calculated using the maximum linear rate observed in each trace (Equation 1) and reported as the average of triplicate measurements. A typical activity is shown.

(3) Perform SDS-PAGE analysis of the reserved samples to confirm the over-expression of ribokinase (32 kDa).

(4) Harvest cells by centrifuging at $10,000 \mathrm{~g}$ for $30 \mathrm{~min}$ at $4^{\circ} \mathrm{C}$. Gently resuspend the cell pellet in $30-\mathrm{mL}$ lysis buffer $2(50 \mathrm{mM}$ potassium phosphate buffer (pH 7.5), 2 mM BME).

(5) Probe-tip sonicate, on ice, for three cycles of $10 \mathrm{~s}$ "on" followed by $10 \mathrm{~s}$ "off," pause for $2 \mathrm{~min}$, and complete three more cycles of $10 \mathrm{~s}$ "on" followed by $10 \mathrm{~s}$ "off."

(6) Pellet the cell debris by centrifugation at $30,000 \mathrm{~g}$ for $30 \mathrm{~min}$ at $4^{\circ} \mathrm{C}$. Transfer the supernatant to a fresh $50-\mathrm{mL}$ conical tube.

(7) Add $3.0 \mathrm{~mL}$ streptomycin sulfate solution $(20 \%$, $\mathrm{wt} / \mathrm{vol}$ ) and mix well. Incubate the sample for $2 \mathrm{~min}$ at $45^{\circ} \mathrm{C}$ and then place on ice. Centrifuge the solution at $30,000 \mathrm{~g}$ for $30 \mathrm{~min}$ at $4^{\circ} \mathrm{C}$ to remove the precipitate. Transfer the supernatant to a fresh 50-mL conical tube.

(8) Add ammonium sulfate to $80 \%$ saturation. Allow the sample to incubate at $4^{\circ} \mathrm{C}$ for at least $15 \mathrm{~min}$. Centrifuge to pellet the precipitate. Resuspend the pellet in 10-mL lysis buffer 2 .

(9) Perform DEAE chromatography with a $500 \mathrm{~mL}$ linear gradient of $0-300 \mathrm{mM} \mathrm{KCl}$ in lysis buffer 2 . Collect 5-8 mL fractions. Assay each column fraction for ribokinase activity (see "RK enzyme activity assay" below) and combine the appropriate fractions.

(10) Concentrate the sample and exchange the buffer using a centrifugal filter (10 kDa NMWL): centrifuge at $4,000 \mathrm{~g}$ in a swinging bucket rotor at $4^{\circ} \mathrm{C}$ until about $1 \mathrm{~mL}$ remains in the upper chamber, add $13 \mathrm{~mL}$ cold lysis buffer 2 , and centrifuge again until 2-3 $\mathrm{mL}$ remains in the upper chamber. Add glycerol to $40 \%$ concentration.
Table 6. Reagents for RK assay.

\begin{tabular}{lc}
\hline Reagent & Final conc. (mM) \\
\hline Triethanolamine buffer (pH 7.3) & 70 \\
PEP & 0.4 \\
$\beta$-NADH & 0.2 \\
ATP & 5 \\
D-Ribose & 5 \\
$\mathrm{MgSO}_{4}$ & 8 \\
$\mathrm{KCl}$ & 10 \\
\hline
\end{tabular}

\section{RK enzyme activity assay}

(1) Prepare $1 \mathrm{~mL}$ of stock solution for each sample to be assayed, using the reagents that are listed in Table 6 .

(2) Add $10 \mathrm{U}$ D-lactic dehydrogenase and $7 \mathrm{U}$ PK per $1 \mathrm{~mL}$ stock solution. Incubate at room temperature for 5-10 min.

(3) Add 1-20 $\mu \mathrm{L}$ of the prepared ribokinase sample to initiate the reaction. Record the absorbance at 340 $\mathrm{nm}$ every $5 \mathrm{~s}$ for $5 \mathrm{~min}$.

(4) Determine the ribokinase activity, in units per $\mathrm{mL}$, of each replicate measurement using equation 1 with $N=1$. Report the final activity as an average of all replicates.

\section{Preparation of APRT and XGPRT}

We prepared APRT and XGPRT using the methods detailed by Tolbert and Williamson [7]. Briefly, an overproducing strain was induced with IPTG, cells were harvested, and ammonium sulfate precipitation and DEAE column chromatography were used to isolate the enzyme.

\section{APRT enzyme activity assay}

(1) In a 15-mL conical tube (wrapped in aluminum foil to protect from light exposure), prepare a $5-\mathrm{mL}$ solution at room temperature containing the reagents that are listed in Table 7.

(2) Add $10 \mathrm{U}$ D-lactic dehydrogenase, $10 \mathrm{U} \mathrm{PK}$, and $10 \mathrm{U}$ myokinase to the 5-mL reagent mixture and equilibrate at room temperature for 5-10 min.

(3) Meanwhile, prepare an APRT enzyme solution in $50 \mathrm{mM}$ Tris-HCl buffer (pH 7.8), containing $10 \mathrm{mM}$ $\mathrm{MgCl}_{2}$.

(4) Add $1.0 \mathrm{~mL}$ of the reaction mixture into a cuvette and blank the spectrophotometer at $340 \mathrm{~nm}$.

(5) Add 10-20 $\mu \mathrm{L}$ of the prepared APRT solution to the cuvette to initiate the reaction. Record the absorbance at $340 \mathrm{~nm}$ every $5 \mathrm{~s}$ for a total of $5 \mathrm{~min}$. Repeat the measurement twice with fresh reagent mixture and enzyme solution.

(6) Determine the APRT activity, in units per $\mathrm{mL}$, for each replicate measurement using Equation 1 with $N=2$. Report the final activity as an average of all replicates (Figure 9). 
Table 7. Reagents for APRT assay.

\begin{tabular}{lc}
\hline Reagent & Final conc. (mM) \\
\hline Tris-HCl (pH 7.8) & 50 \\
$\mathrm{MgCl}_{2}$ & 10 \\
PRPP & 1.5 \\
Adenine- $\mathrm{HCl}$ & 1.5 \\
PEP & 1.0 \\
$\beta$-NADH & 0.2 \\
ATP & 3.0 \\
\hline
\end{tabular}

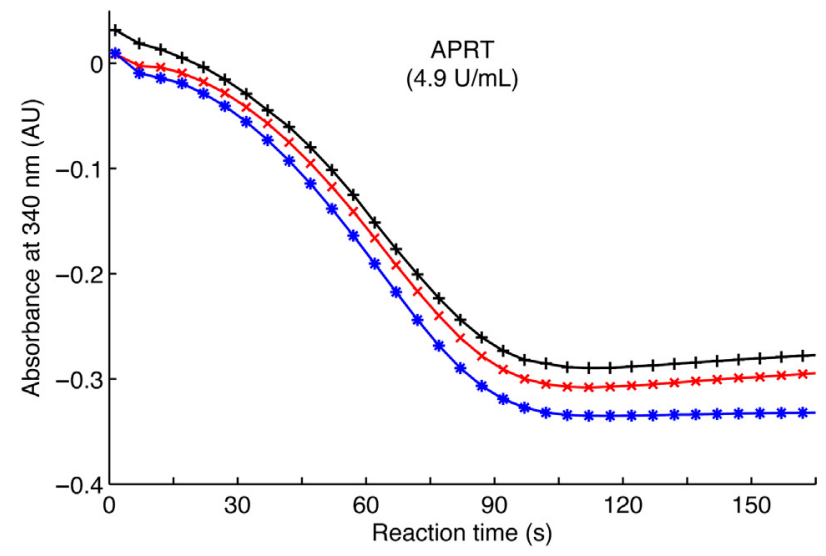

Figure 9. Enzymatic activity assay of APRT. The activity was calculated using the maximum linear rate observed in each trace (Equation 1) and reported as the average of triplicate measurements. A typical activity is shown.

\section{XGPRT enzyme activity assay}

(1) In a $15 \mathrm{~mL}$ conical tube, mix the reagents that are listed in Table 8 to give a final volume of $2 \mathrm{~mL}$.

(2) Add $1 \mathrm{U}$ inorganic pyrophosphatase and $1 \mathrm{mg}$ guanine.

(3) Initiate the reaction by adding 20-30 $\mu \mathrm{L}$ XGPRT.

(4) Over a period of $10 \mathrm{~min}$, remove $100-\mu \mathrm{L}$ aliquots from the reaction mixture for every $2 \mathrm{~min}$.

(5) Filter each aliquot and transfer to an HPLC sample vial.

(6) Chromatograph the samples using reverse-phase HPLC (Figure 10).

(7) Quantify the peak corresponding to GMP to estimate the activity of the enzyme.

\section{ATP, GTP, and UTP synthesis}

(1) Weigh the reagents listed in Table 9 into a clean, dry 25-mL round bottom flask.

(2) Weigh the appropriate base into the flask according to the NTP that is being synthesized:

(a) For synthesis of ATP: $45 \mathrm{mg}$ adenine $\cdot \mathrm{HCl}$

(b) For synthesis of GTP: $45 \mathrm{mg}$ guanine

(c) For synthesis of UTP: $45 \mathrm{mg}$ uracil
Table 8. Reagents for XGPRT assay.

\begin{tabular}{lc}
\hline Reagent & Final conc. (mM) \\
\hline PRPP & 1.0 \\
$\mathrm{MgCl}_{2}$ & 10 \\
Potassium phosphate buffer $(\mathrm{pH} 7.5)$ & 50 \\
\hline
\end{tabular}

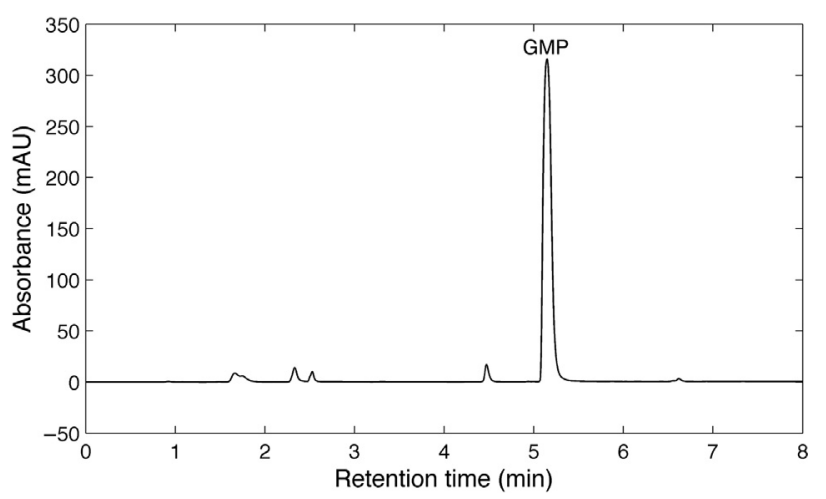

Figure 10. HPLC analysis of the enzymatic activity assay of XGPRT.

Table 9. Reagents for ATP, GTP, and UTP synthesis.

\begin{tabular}{lc} 
Reagent & Amount $(\mathbf{m g})$ \\
\hline D-[X- $\left.{ }^{2} H\right]$ ribose & 20 \\
DTT & 23 \\
3-PGA & 170 \\
\hline
\end{tabular}

Note: $X=$ either $1^{\prime}, 2^{\prime \prime}, 3^{\prime}, 4^{\prime}$, or $5^{\prime}, 5^{\prime \prime}$.

(3) Add $14.5 \mathrm{~mL}$ potassium phosphate buffer and a stir bar to the flask and begin stirring gently.

(4) Add $0.3 \mathrm{~mL} 0.5 \mathrm{M} \mathrm{MgCl}_{2}$ to the flask.

(5) Adjust the $\mathrm{pH}$ dropwise to 7.6 with $1 \mathrm{M} \mathrm{KOH}$.

(6) Remove oxygen gas from the solution in the fume hood by bubbling with nitrogen gas for 15-20 min. TIMING: Work quickly to minimize the reintroduction of oxygen into the reaction mixture.

(7) Add the enzymes listed in Table 10 to the reaction mixture.

(8) Add the appropriate phosphoribosyltransferase enzyme to the reaction according to which rNTP is being synthesized:

(a) For synthesis of ATP: 1 U APRT

(b) For synthesis of GTP: 0.2 U XGPRT

(c) For synthesis of UTP: $40 \mu \mathrm{L}$ UPRT

(9) Check the $\mathrm{pH}$ and adjust to 7.6 if necessary. Transfer a $50-\mu \mathrm{L}$ aliquot of the reaction mixture to a fresh $1.5-\mathrm{mL}$ microcentrifuge tube and store at -20 or $-80^{\circ} \mathrm{C}$. This sample will be used later for HPLC analysis. 
Table 10. Enzymes for ATP, GTP, and UTP synthesis.

\begin{tabular}{lc}
\hline Enzyme & Activity (U) \\
\hline Phosphoglycerate mutase & 40 \\
Enolase & 60 \\
Pyruvate kinase & 65 \\
Myokinase & 8 \\
Ribokinase & 2 \\
PRPP synthetase & 1 \\
\hline
\end{tabular}

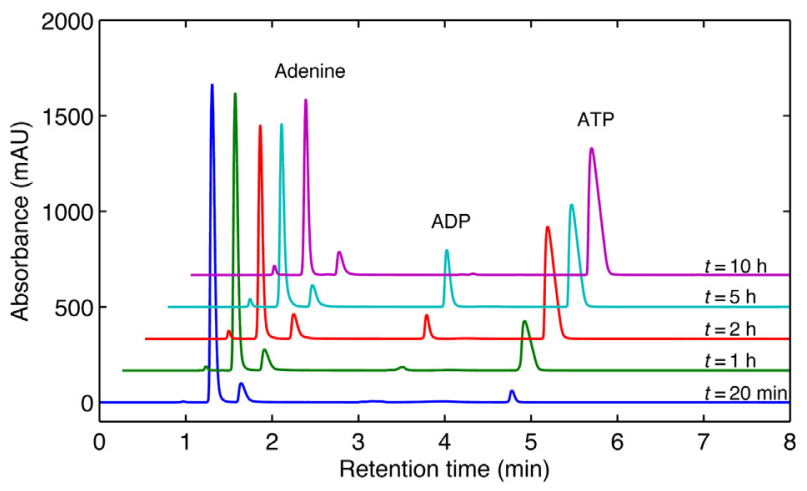

Figure 11. HPLC chromatograms of the reaction mixture used for the synthesis of $\left[4^{\prime}-{ }^{2} \mathrm{H}\right] \mathrm{ATP}$, after $0,1,2,5$, and $10 \mathrm{~h}$. Chromatograms are shifted by a fixed percentage in time and absorbance for visual clarity.

(10) Initiate the reaction by adding $10 \mu \mathrm{L}$ of a $75 \mathrm{mM}$ ATP stock solution, or, if applicable, the same deuterated analog of ATP that is being synthesized. Remove a $50-\mu \mathrm{L}$ aliquot and store it in a $-20^{\circ} \mathrm{C}$ freezer for later HPLC analysis. Inflate a balloon with nitrogen gas and place it over the neck of the round bottom flask. Create a seal by covering with a few layers of paraffin film.

(11) After $1 \mathrm{~h}$, check the $\mathrm{pH}$ and adjust to 7.6, if necessary. Reserve a $50-\mu \mathrm{L}$ aliquot for HPLC analysis.

(12) After $2 \mathrm{~h}$, add $170 \mathrm{mg}$ 3-PGA disodium and adjust the $\mathrm{pH}$ to 7.6 , if necessary. Reserve a $50-\mu \mathrm{L}$ aliquot for HPLC analysis. For GTP synthesis, add $2 \mathrm{U}$ guanylate kinase. For UTP synthesis, add $1 \mathrm{U}$ NMPK. NOTE: Check the $\mathrm{pH}$ of the reaction mixture periodically and adjust to 7.6 if necessary. Reserve an aliquot of the reaction mixture and store in the freezer at various time points (e.g., 1, 2, 5, 10, and $24 \mathrm{~h}$ ) as needed for HPLC analysis.

(13) After $5 \mathrm{~h}$, add $170 \mathrm{mg} 3$-PGA to the reaction mixture and continue stirring.

(14) Continue stirring until the reaction has gone to completion, which can typically take between 5 and $24 \mathrm{~h}$, as determined by HPLC (Figure 11).

(15) Remove proteins and particulates: transfer the crude reaction mixture to a centrifugal filter (10 $\mathrm{kDa}$ NMWL) and centrifuge at $4,000 \mathrm{~g}$ in a
Table 11. Reagents for CTP synthesis.

\begin{tabular}{lc}
\hline Reagent & Final conc. (mM) \\
\hline $\mathrm{MgCl}_{2}$ & 10.0 \\
ATP & 2.5 \\
GTP & 0.2 \\
{$\left[X-{ }^{2} \mathrm{H}\right]$ UTP } & 1.0 \\
\hline
\end{tabular}

Note: $X=$ either $1^{\prime}, 2^{\prime \prime}, 3^{\prime}, 4^{\prime}$, or $5^{\prime}, 5^{\prime \prime}$.

swinging bucket rotor for $15 \mathrm{~min}$ or until all liquid has filtered through to the bottom of the tube. CRITICAL: Make sure the centrifuge is properly balanced during operation.

(16) Prepare an ethanol/dry ice bath in a heavily insulated vessel (such as a Dewar or Styrofoam box). Immerse the sample tube into the ethanol/dry ice bath at an angle. Rotate until all of the sample liquid is frozen solid. Uncap the tube, cover with two layers of paraffin film and poke several small holes in the film using a fine-gauge needle. Lyophilize the sample overnight or until the sample is dry. Store at $4^{\circ} \mathrm{C}$ for short times $\left(<1\right.$ day) or $-20^{\circ} \mathrm{C}$ or below for longer times.

\section{CTP synthesis}

(1) In a $20-\mathrm{mL}$ glass scintillation vial, add the reagents listed in Table 11 to $5 \mathrm{~mL}$ of $50 \mathrm{mM}$ Tris- $\mathrm{HCl}$ buffer (pH 7.8).

(2) Add a stir bar to the vial and begin stirring. Remove a $50-\mu \mathrm{L}$ aliquot for HPLC analysis and store at $-20^{\circ} \mathrm{C}$.

(3) Initiate the reaction by adding glutamine to a final concentration of $1 \mathrm{mM}$.

(4) Remove a $50-\mu \mathrm{L}$ aliquot each hour. Store at $-20^{\circ} \mathrm{C}$ for later HPLC analysis.

(5) After $10 \mathrm{~h}$, or when the reaction is complete as determined via HPLC analysis, syringe-filter the solution into a fresh scintillation vial through a filter with pore size $0.45 \mu \mathrm{m}$. Flash freeze the filtered solution in an ethanol/dry ice bath. Lyophilize overnight or until all water has been removed.

\section{HPLC analysis of NTPs}

(1) In $200-\mu \mathrm{L}$ conical HPLC sample vials, prepare $0.5 \mathrm{mM}$ solutions of standard and deuterated ribonucleoside $5^{\prime}$-triphosphates in Milli-Q-purified water $(\geq 18.2 \mathrm{M} \Omega \mathrm{cm})$.

(2) Prepare $1 \mathrm{~L}$ each of the following HPLC-grade mobile phases: water, $1.0 \mathrm{M} \mathrm{NaCl}$, and $0.1 \mathrm{M} \mathrm{NaOH}$. Filter the $\mathrm{NaCl}$ and $\mathrm{NaOH}$ solutions through a $0.45 \mu \mathrm{M}$ membrane. Set up the solvent channels as (A) water, (B) $1.0 \mathrm{M} \mathrm{NaCl}$, and (C) $0.1 \mathrm{M} \mathrm{NaOH}$.

(3) Equilibrate the HPLC system (DNAPac PA 200 analytical column) at a flow rate of $1.4 \mathrm{~mL} / \mathrm{min}$ with $92.5 \% \mathrm{~A}, 5 \% \mathrm{~B}$, and $2.5 \% \mathrm{C}$, at a column 
temperature of $30^{\circ} \mathrm{C}$. Monitor the baseline absorbance at $260 \mathrm{~nm}$.

(4) Set up a batch run to perform 1-40 $\mu \mathrm{L}$ injections of a blank water solution, three consecutive injections of an NTP standard solution, at least two injections of a deuterated NTP solution, and one final standard NTP injection.

(5) For each sample, pre-equilibrate the column for 5 min, inject the sample, run a linear gradient from $5 \%$ to $40 \%$ B (with constant $2.5 \% \mathrm{C}$ ) from 0 to $10 \mathrm{~min}$, increase to $80 \% \mathrm{~B}$, and hold for $3 \mathrm{~min}$.

\section{PURIFICATION OF DEUTERATED NTPS Boronate affinity column chromatography}

(1) Set up a glass chromatography column in the cold room (a flow adapter is not recommended). Suspend $3 \mathrm{~g}$ Affi-Gel boronate affinity resin in $50-\mathrm{mL}$ cold $0.5 \mathrm{M}$ ammonium bicarbonate buffer ( $\mathrm{pH} 9.5)$, let sit for $10 \mathrm{~min}$, and then pack the resin into the column while maintaining a steady flow. Collect the flowthrough into a designated waste container. Equilibrate the column with at least five column volumes of cold $0.5 \mathrm{M}$ ammonium bicarbonate buffer ( $\mathrm{pH} 9.5$ ). CRITICAL: Perform boronate affinity chromatography at $4^{\circ} \mathrm{C}$, as resin binding affinity can be drastically weakened at higher temperatures.

(2) Meanwhile, dissolve the lyophilized NTP residue in $10 \mathrm{~mL}$ of cold $0.5 \mathrm{M}$ ammonium bicarbonate, let it sit for 5-10 $\mathrm{min}$, and then filter the solution using a syringe filter $(0.45 \mu \mathrm{m})$ into a fresh conical tube. NOTE: Filtering samples will prolong the lifetime of the affinity resin and column.

(3) Apply the sample directly to the top of the affinity resin. Continue washing the column with cold $0.5 \mathrm{M}$ ammonium bicarbonate. Monitor and record the absorbance value at $260 \mathrm{~nm}$.

(4) When the A260 drops below $\sim 0.1 \mathrm{AU}$, elute the bound material with cold acidified dH2O. Collect $5 \mathrm{~mL}$ fractions. Combine fractions having an absorbance $>0.1 \mathrm{AU}$ and transfer to a clean, dry lyophilization flask. Flash freeze the sample in an ethanol/dry ice bath. Lyophilize overnight or until all water has been removed.

(5) Resuspend the residue in a minimal amount of dH2O $(\sim 5 \mathrm{~mL})$, making sure to rinse the flask walls to maximize recovery of solute. Repeat the flash freezing and lyophilization process.

\section{Ion-exchange column chromatography}

(1) Set up a glass chromatography column on the benchtop at room temperature. Pour, in one motion, $\sim 30$ mL DEAE-650M resin into the column with the stopcock in the open position. Continue to add $5 \mathrm{mM}$ ammonium bicarbonate ( $\mathrm{pH}$ 9.5) while collecting the flow-through in a large marked waste container. Equilibrate the column with at least five column

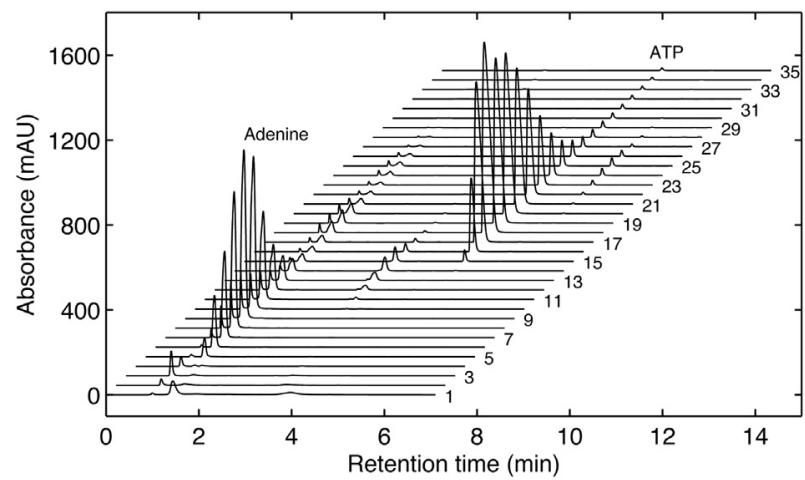

Figure 12. HPLC analysis of fractions collected from DEAE ionexchange chromatographic purification of $\left[4^{\prime}-{ }^{2} \mathrm{H}\right] \mathrm{ATP}$. Chromatograms are shifted by a fixed percentage in time and absorbance for visual clarity. Fraction numbers are labeled at the beginning of each chromatogram and increase from the bottom left to the top of the figure.

volumes of $5 \mathrm{mM}$ ammonium bicarbonate. NOTE: The use of a flow adapter is recommended.

(2) Meanwhile, prepare the NTP sample by resuspending the lyophilized residue in $15 \mathrm{~mL}$ of $50 \mathrm{mM}$ ammonium bicarbonate, let sit for 5-10 min, and pass through a syringe filter with a pore size of $0.45 \mu \mathrm{m}$. NOTE: Filtering samples before loading them onto the column will prolong the lifetime of the column and resin.

(3) Load the sample into the flow adapter, wash the column with one column volume of $5 \mathrm{mM}$ ammonium bicarbonate, and begin a linear gradient of ammonium bicarbonate buffer $(\mathrm{pH} 9.5)$ from 5 to $500 \mathrm{mM}$. Collect $5 \mathrm{~mL}$ fractions. Determine via HPLC which fractions contain the deuterated NTP of interest (Figure 12).

(4) Combine the appropriate fractions in a clean, dry lyophilization vessel, flash freeze in an ethanol/dry ice bath, and lyophilize overnight or until all liquid has been removed.

(5) Resuspend the residue in a minimal amount of $\mathrm{dH}_{2} \mathrm{O}$ and repeat flash freezing and lyophilization. TIP: A third round of resuspension and lyophilization is sometimes necessary if there is too much residual salt.

\section{lon-pair reversed-phase HPLC}

(1) Turn on the UV detector, set the column temperature to $30^{\circ} \mathrm{C}$, and equilibrate the reverse-phase column with a mobile phase of $25 \mathrm{mM}$ TEAA buffer ( $\mathrm{pH}$ 6.5) at a flow rate of $5.0 \mathrm{~mL}$ per min. Set up a linear gradient from 0 to $8 \%$ acetonitrile in $25 \mathrm{mM}$ TEAA buffer (pH 6.5) over 16 min.

(2) Meanwhile, dissolve the lyophilized residue in $2.0 \mathrm{~mL}$ or less of mobile phase, let the sample sit 
for 5-10 $\mathrm{min}$, and then pass the solution through a syringe filter with a $0.45-\mu \mathrm{m}$ pore size.

(3) Manually inject $250 \mu \mathrm{L}$ of a mobile phase blank solution and observe the baseline absorbance at $260 \mathrm{~nm}$.

(4) Perform at least three manual injections of $250 \mu \mathrm{L}$ of an NTP standard solution.

(5) Perform as many $250-\mu \mathrm{L}$ sample injections as needed until the sample is consumed. Collect every fraction that contains the NTP of interest (see Figure 13).

(6) Pool the appropriate fractions into a lyophilization flask, flash freeze in an ethanol/dry ice bath, and lyophilize overnight or until the sample is dry.

\section{MASS SPECTROMETRY OF PURIFIED NTPS}

(1) In $200 \mu \mathrm{L}$ HPLC conical sample vials, prepare 0.1 $\mathrm{mg} / \mathrm{mL}$ solutions of standard and purified deuterated ribonucleoside $5^{\prime}$-triphosphates in high quality water $(\geq 18.2 \mathrm{M} \Omega \mathrm{cm})$. Prepare a blank sample containing the same water used to dissolve the NTPs.

(2) Set up an HPLC-MS instrument to perform $10 \mu \mathrm{L}$ sample injections directly into the mass spectrometer operating in positive-ion mode. Use a mobile

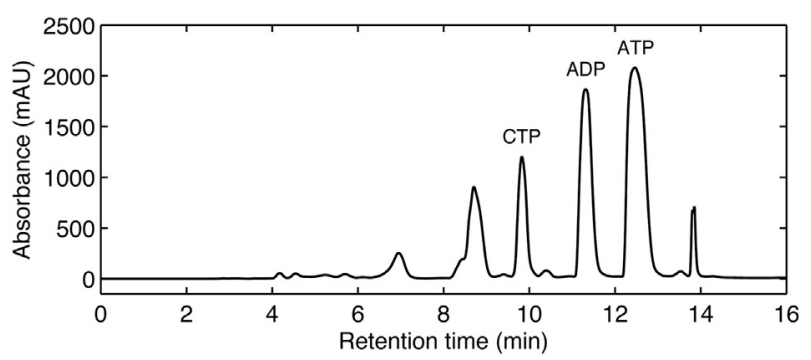

Figure 13. Chromatogram of semi-preparative scale purification of $\left[4^{\prime}-{ }^{2} \mathrm{H}\right] \mathrm{CTP}$ by ion-pair reversed-phase HPLC. phase of $0.1 \%$ formic acid in water with a flow rate of $0.2 \mathrm{~mL}$ per min.

(3) Inject $10 \mu \mathrm{L}$ of the water blank before and after each NTP sample injection to eliminate crossover contamination.

(4) Verify the accuracy of the spectrometer using the mass spectrum of the standard NTP solution. Compare the experimental mass-to-charge ratio to that expected for the standard and deuterated NTP (Figures 14 and 15).

\section{USE OF DEUTERATED NUCLEOTIDES AS PROBES OF RNA STRUCTURE Preparation of RNA by in vitro transcription}

(1) Prepare a stock solution of a deuterated NTP $(75 \mathrm{mM})$ in RNase-free water.

(2) Set up two 20- $\mu \mathrm{L}$-scale transcription reactions according to the T7 MEGAShortscript kit instructions. For one of the samples, substitute $2 \mu \mathrm{L}$ deuterated NTP solution in place of the appropriate stock solution included with the kit.

(3) Incubate for at least $3 \mathrm{~h}$ at $37^{\circ} \mathrm{C}$. Add $1 \mu \mathrm{L}$ TURBO DNase and incubate for an additional $15 \mathrm{~min}$ at $37^{\circ} \mathrm{C}$.

(4) Filter each reaction mixture through a NucAway spin column according to the manufacturer's instructions. Elute in 40- $\mu \mathrm{L}$ RNase-free water.

(5) Add 4- $\mu \mathrm{L}$ ammonium acetate solution (5 M) to each tube and mix. Precipitate the RNA by adding $150 \mu \mathrm{L}$ cold $100 \%$ ethanol and mix well. Incubate the samples at $-80^{\circ} \mathrm{C}$ for $1 \mathrm{~h}$.

(6) Centrifuge the precipitated RNA samples at 20,000g for $30 \mathrm{~min}$ at $4^{\circ} \mathrm{C}$.

(7) Using a $200-\mu \mathrm{L}$ pipet tip, carefully withdraw the supernatant without disturbing the pellet, which contains the RNA.

(8) Wash the pellet with $200 \mu \mathrm{L}$ of cold $70 \%$ ethanol. Centrifuge at $13,000 \mathrm{~g}$ for $15 \mathrm{~min}$ at $4^{\circ} \mathrm{C}$.
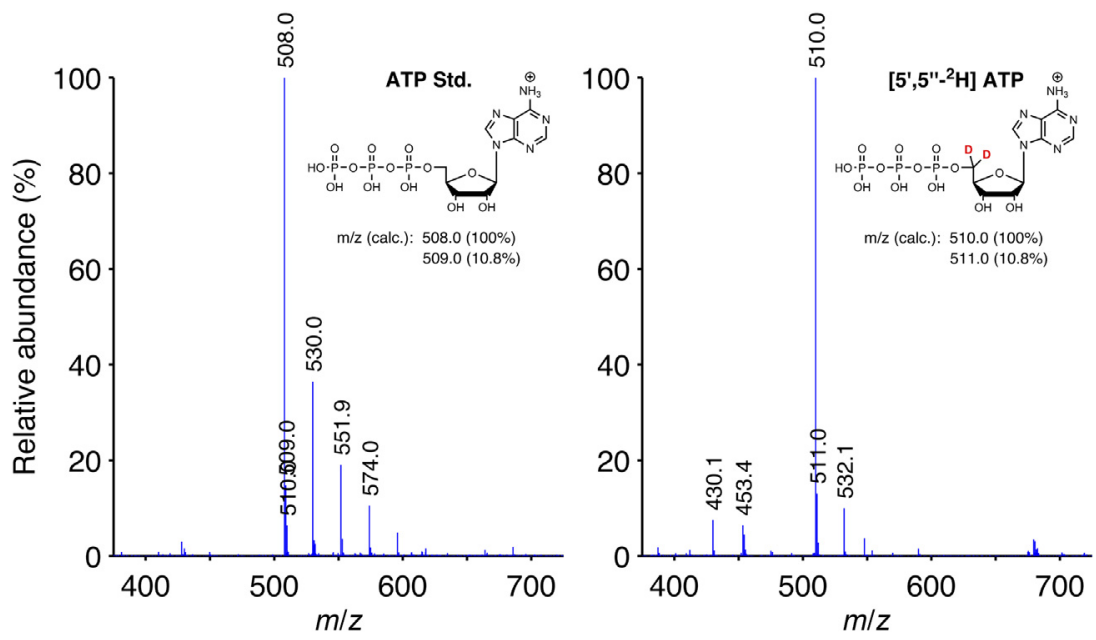

Figure 14. Mass spectra of an ATP disodium standard (left) and $\left[5^{\prime}, 5^{\prime \prime}-{ }^{2} \mathrm{H}\right]$ ATP (right). The insets depict the structures of the most abundant molecular ion in each sample and list the expected $\mathrm{m} / \mathrm{z}$. The expected natural isotopic abundances are noted in parentheses. Deuterium atoms are colored red. 


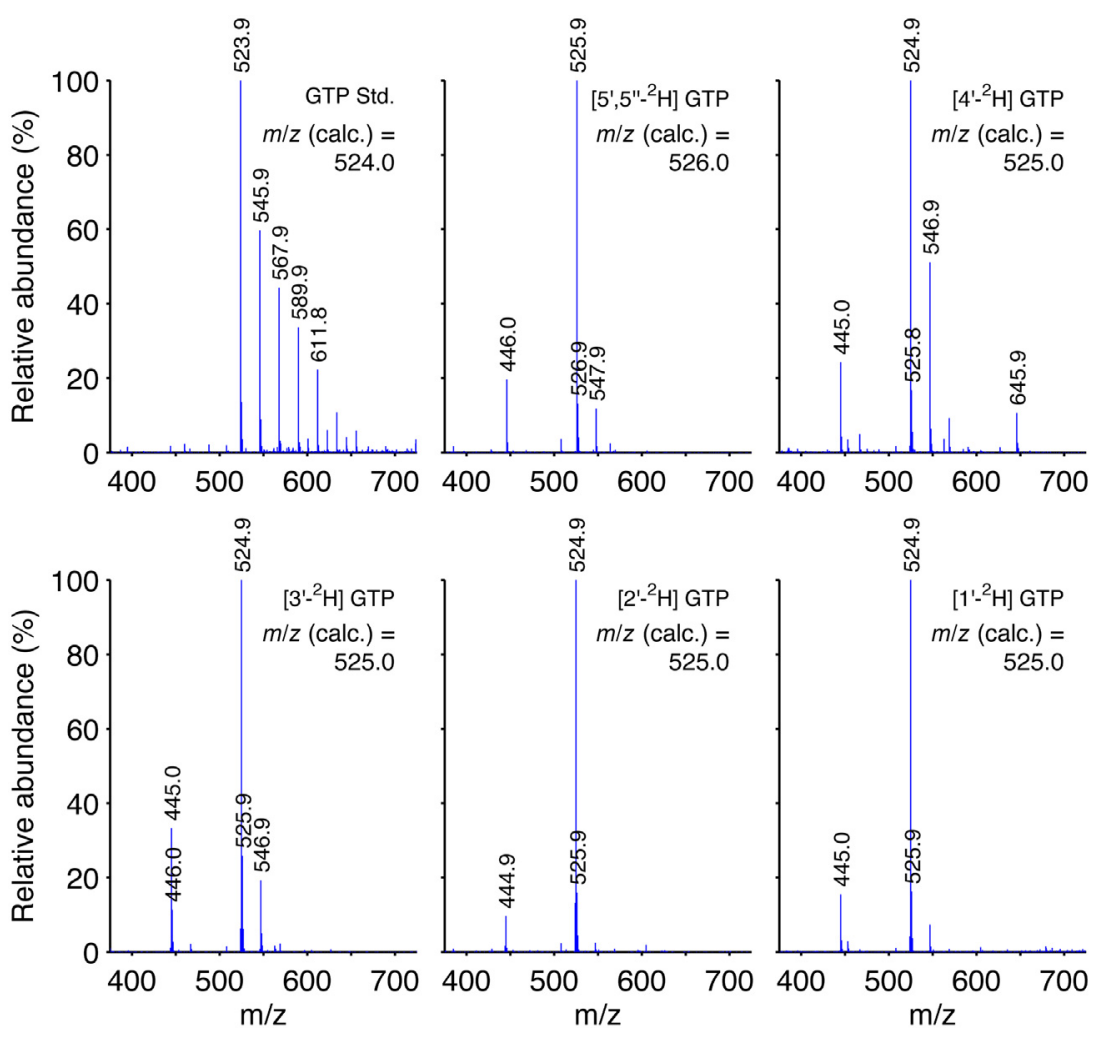

Figure 15. Mass spectra of a GTP disodium standard (A) and deuterated GTP analogs (B-F). Calculated $m / z$ values shown in the top right of each panel correspond to the $[\mathrm{M}+\mathrm{H}]^{+}$molecular ion of GTP.

(9) Discard the supernatant. Dry the pellets either on the benchtop or under vacuum.

(10) Resuspend the RNA pellets in $10 \mu \mathrm{L}$ RNase-free water.
(5) To remove polyacrylamide gel pieces, transfer the RNA solution to a $1.5 \mathrm{~mL}$ centrifugal filter (Ambion) and centrifuge for $5 \mathrm{~min}$ at $20,000 \mathrm{~g}$.

(6) Ethanol precipitate and dry the RNA sample.

\section{$5^{\prime}$-end labeling of RNA with ${ }^{32} \mathrm{P}$}

(1) Phosphatase reaction, to remove the $5^{\prime}$-phosphate: In a $1.5-\mathrm{mL}$ microcentrifuge tube, prepare $19 \mu \mathrm{L}$ of a solution containing 50 pmol RNA in $1 \times$ AP buffer. Add $1 \mu \mathrm{L}$ AP enzyme to the reaction and incubate for $30 \mathrm{~min}$ at $37^{\circ} \mathrm{C}$. Heat the sample for $5 \mathrm{~min}$ at $65^{\circ} \mathrm{C}$ to inactivate the enzyme.

(2) T4 PNK reaction, to add $5^{\prime}{ }_{-}^{32} \mathrm{P}$ : To the reaction tube containing dephosphorylated RNA, add $11 \mu \mathrm{L}$ RNasefree water, $5 \mu \mathrm{L}$ T4 PNK buffer $(10 \times), 1 \mu \mathrm{L}$ T4 PNK enzyme, and $2.5 \mu \mathrm{L}\left[\gamma^{-32} \mathrm{P}\right] \mathrm{ATP}$ to give a final volume of $40 \mu \mathrm{L}$. Incubate the sample for $1 \mathrm{~h}$ at $37^{\circ} \mathrm{C}$.

(3) Add $40 \mu \mathrm{L}$ Gel Loading Buffer II (from the T7 MEGAShortscript transcription kit) and mix well. Purify radiolabeled RNA by electrophoresis on a $12-15 \%$ denaturing PAGE gel.

(4) Excise the gel band containing radiolabeled RNA and place into a fresh $1.5 \mathrm{~mL}$ microcentrifuge tube. Using a pipet tip, crush the gel slice against the wall of the tube. Elute the RNA by soaking in $150 \mu \mathrm{L}$ buffer (25 mM phosphate ( $\mathrm{pH} 7.6$ ), 0.3 M sodium acetate, $0.1 \mathrm{M} \mathrm{KCl}$ ) for $1 \mathrm{~h}$ at $4^{\circ} \mathrm{C}$.

\section{Hydroxyl radical cleavage reaction}

(1) In separate 1.5-mL microcentrifuge tubes, place 40 kcpm of singly end-labeled nondeuterated (ND) and deuterated RNA in a total volume of $7 \mu \mathrm{L}$ of potassium phosphate buffer ( $\mathrm{pH}$ 7.6). Also prepare one ND and one deuterated control RNA sample.

(2) Renature the RNA by incubating the samples at $90^{\circ} \mathrm{C}$ for $2 \mathrm{~min}$ and then cooling on the benchtop for $10 \mathrm{~min}$.

(3) To initiate the hydroxyl radical cleavage reaction for the experimental samples, carefully spot $1 \mu \mathrm{L}$ each of the following three reagent solutions as separate drops on the wall of the sample tube: $10 \mathrm{mM}$ sodium ascorbate, $1.2 \% \mathrm{H}_{2} \mathrm{O}_{2}$, and iron(II)-EDTA ( $1 \mathrm{mM}$ iron (II)/2 mM EDTA). For the control samples, substitute RNase-free water for each of the three hydroxyl radical reagents. CRITICAL: Hydroxyl radical cleavage reagents should be freshly prepared. Reagents used to carry out hydroxyl radical cleavage should not be premixed before being added to the RNA sample. Premixing the reagents initiates the Fenton reaction prematurely, expending hydroxyl radicals before the target RNA is added. 
(4) With a flick of the wrist or a quick spin in a benchtop centrifuge, quickly add the cleavage reagent drops from the tube wall to the sample and mix gently. Immediately begin timing the reaction. Let the reaction proceed for $2 \mathrm{~min}$, and then quench by adding $1 \mu \mathrm{L}$ of $100 \mathrm{mM}$ thiourea. NOTE: The reaction time can be varied (1-5 $\mathrm{min}$ ) to optimize the extent of RNA cleavage. Separate reactions should be carried out in parallel to determine the reaction time that gives optimum cleavage. CRITICAL: The Fenton reaction is initiated by mixing the hydroxyl radical reagents, which generates the radical species necessary for cleavage of the RNA backbone. It is important to stop the cleavage reaction by adding the thiourea stop solution, which quenches the reaction by reacting with any remaining hydroxyl radicals.

(5) Add $4 \mu \mathrm{L}$ ammonium acetate solution (5 M) to each tube and mix. Precipitate the RNA by adding $150 \mu \mathrm{L}$ cold $100 \%$ ethanol and mix well. Incubate the samples at $-80^{\circ} \mathrm{C}$ for $1 \mathrm{~h}$.

(6) Centrifuge the precipitated RNA samples at 20,000 g for $30 \mathrm{~min}$ at $4^{\circ} \mathrm{C}$.

(7) Using a $200-\mu \mathrm{L}$ pipet tip, carefully remove the supernatant without disturbing the pellet, which contains the RNA. Check the tube using a Geiger counter to ensure that a substantial fraction $(>60 \%)$ of the radioactivity is retained in the pellet after discarding the supernatant.

(8) Wash the pellet with $200 \mu \mathrm{L}$ of cold $70 \%$ ethanol. Centrifuge at $13,000 \mathrm{~g}$ for $15 \mathrm{~min}$ at $4^{\circ} \mathrm{C}$.

(9) Discard the supernatant and dry the pellets either on the benchtop or under vacuum.

(10) Resuspend the RNA pellets in 4- $\mu \mathrm{L}$ Gel Loading Buffer II (from the T7 MEGAShortscript transcription kit) and analyze using high-resolution denaturing PAGE.

\section{Denaturing polyacrylamide gel electrophoresis}

(1) Siliconize the larger of the two glass plates with 0.5-mL Sigmacote.

(2) Assemble the gel plate sandwich with spacers and comb (0.33-mm thickness).

(3) Prepare $70 \mathrm{~mL}$ of a $20 \%$ acrylamide:bisacrylamide (19:1) solution containing 7-8 M urea. Degas the solution for 5 min under vacuum. A 20\% gel is appropriate for short RNAs, like the SRL. Use a lower gel percentage if studying a larger RNA molecule.

(4) Initiate gel polymerization by adding $250 \mu \mathrm{L} 10 \%$ (wt/vol) APS and $40 \mu \mathrm{L}$ TEMED to the acrylamide/ urea solution. Pour the gel and allow to polymerize for $\sim 1 \mathrm{~h}$.

(5) Mount the gel in the gel electrophoresis apparatus. Pre-run the gel at constant power (65 W) for at least 30 min. CRITICAL: The power at which the gel runs should be adjusted so that the surface temperature of the gel plates does not exceed $55^{\circ} \mathrm{C}$.
(6) Heat the RNA samples at $95^{\circ} \mathrm{C}$ for 2 min to denature the RNA. Load all $4 \mu \mathrm{L}$ of each sample into a lane of the pre-run gel.

(7) Electrophorese at constant power $(65 \mathrm{~W})$ for sufficient time to resolve the region of interest ( $3.5 \mathrm{~h})$. The bromophenol blue and xylene cyanol dyes that are included in the gel-loading buffer provide convenient visible markers for estimating the optimum time for electrophoresis.

(8) After electrophoresis, allow the gel to cool to room temperature and remove from the apparatus.

(9) Place the gel sandwich on a lab bench and carefully remove one glass plate (the plate that was siliconized) from the gel assembly. Place a layer of plastic wrap on the exposed gel while trying to minimize wrinkles in the plastic.

(10) Invert the assembly. Pull the plastic away from the glass plate slowly and carefully, peeling the gel along with the plastic.

(11) Cover the exposed side of the gel with Whatman chromatography paper. Take care to avoid wrinkles between the gel and the Saran wrap. The presence of wrinkles can lead to inefficient gel imaging during exposure to the phosphor screen.

(12) Dry the gel using the gel dryer for about $2 \mathrm{~h}$ at $80^{\circ} \mathrm{C}$. The gel drying conditions should be optimized for the acrylamide percentage of the gel and the gel dryer that is used. The drying conditions may be varied by adjusting the drying time or the length of time that the vacuum is applied to the gel.

(13) Place the dried gel in an exposure cassette at room temperature and expose to a phosphor screen. The exposure time can vary from less than $1 \mathrm{~h}$ to $18 \mathrm{~h}$ depending upon the level of radioactivity of the RNA sample.

(14) Scan the phosphor screen using a phosphorimager (Typhoon Trio or equivalent) to produce an image file with a gel extension. See Figure 16 for representative cleavage intensity scans of two lanes from a phosphor image containing deuterated (black) and nondeuterated (red) SRL RNA.

\section{Measurement of the deuterium kinetic isotope effect on hydroxyl radical cleavage}

(1) Process the gel file by importing it into SAFA [20] (a computer program for semi-automated footprint analysis). Use SAFA to fit and integrate the gel bands in each of the lanes containing a hydroxyl radicalcleaved RNA sample.

(2) Using the band integrals exported from SAFA, calculate the ratio of the amount of cleavage of the nondeuterated sample to the deuterated sample, at each nucleotide position of interest [8] (Figure 17).

(3) A deuterium kinetic isotope effect is present when the calculated ratio $\left(k_{\mathrm{H}} / k_{\mathrm{D}}\right)$ is greater than 1.0 . Residues lacking deuterium should have a $k_{\mathrm{H}} / k_{\mathrm{D}}$ ratio of 1.0 and so can be used as internal standards to help assess the quality of the data. 


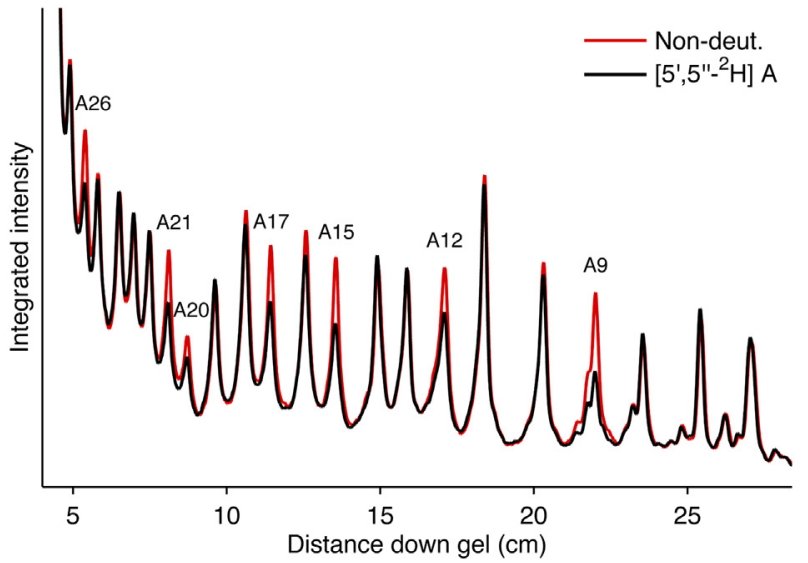

Figure 16. Representative intensity traces from a denaturing polyacrylamide gel on which was separated hydroxyl radical cleavage products of SRL RNA that was synthesized using nondeuterated ATP (red) or [5, $5^{\prime \prime}-{ }_{-}^{2}$ H]ATP (black). The SRL RNA molecule is $29 \mathrm{nt}$ in length. Labels indicate the positions of adenines in the SRL sequence. A clear difference in band intensity between control and deuterated samples is seen only at adenine residues, because of the deuterium kinetic isotope effect on cleavage by the hydroxyl radical [8].

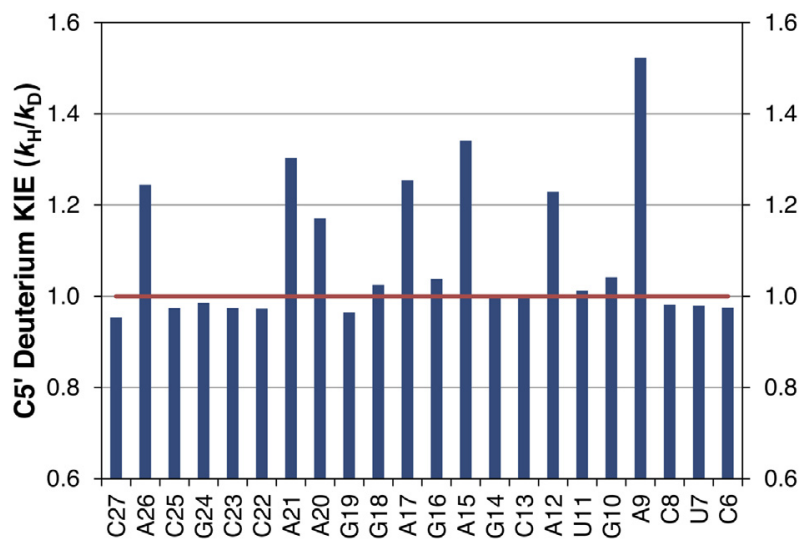

Figure 17. Deuterium kinetic isotope effects calculated by taking the ratio of the cleavage integral of the nondeuterated to the deuterated RNA sample at each residue (for example, the experiment shown in Figure 16). Peak integrals were calculated using the SAFA software package. Significant deuterium kinetic isotope effects $\left(k_{\mathrm{H}} / k_{\mathrm{D}}>1\right.$, above red line) are seen only at the adenine residues, which were deuterated at the $5^{\prime}$ position of the ribose.

\section{CONCLUSIONS}

The protocol described here has been used to synthesize specifically deuterated analogs of each ribonucleoside $5^{\prime}$-triphosphate. As an example of the utility of deuterated nucleotides for RNA structural biology, five deuterated analogs of each ribonucleotide were synthesized and incorporated into the SRL RNA molecule to study mechanistic and structural aspects of RNA strand cleavage by the hydroxyl radical [8]. We anticipate that the use of specifically deuterated nucleotides for chemical probe analysis of RNA will be valuable in the structural elucidation of the rapidly increasing collection of RNA molecules that continue to be discovered. This synthesis protocol will contribute to this effort by facilitating the easy availability of specifically deuterated ribonucleotides.

\section{ACKNOWLEDGMENTS}

We are grateful to Jamie Williamson (The Scripps Research Institute) for his generous gifts of cells and plasmids that we used for the expression of several of the enzymes in this protocol. We thank Mark J. Jedrzejas (Children's Hospital Oakland Research Institute) for generously providing us with the expression vector for iPGM. We are grateful to Clotilde Carlow (New England Biolabs) for her generous gift of the expression plasmid for His-tagged iPGM. We express our thanks to Norman Lee (CIC, Boston University) for providing assistance with mass spectrometry of nucleotide samples. Financial support for this work was provided by the National Science Foundation [MCB-0843265 to T.D.T.].

\section{REFERENCES}

[1] Lu K, Miyazaki Y, Summers MF. Isotope labeling strategies for NMR studies of RNA. J Biomol NMR. 2010;46(1):113-25. doi:10.1007/s10858-009-9375-2

[2] Kozarich JW, Worth L, Frank BL, Christner DF, Vanderwall DE, Stubbe J. Sequence-specific isotope effects on the cleavage of DNA by bleomycin. Science. 1989;245(4924):1396-9. doi:10.1126/ science. 2476851

[3] Balasubramanian B, Pogozelski WK, Tullius TD. DNA strand breaking by the hydroxyl radical is governed by the accessible surface areas of the hydrogen atoms of the DNA backbone. Proc Natl Acad Sci USA. 1998;95(17):9738-43. doi:10.1073/pnas. 95.17.9738

[4] Burgess K, Cook D. Syntheses of nucleoside triphosphates. Chem Rev. 2000;100(6):2047-60. doi:10.1021/cr990045m

[5] Scott LG, Tolbert TJ, Williamson JR. Preparation of specifically ${ }^{2} \mathrm{H}$ - and ${ }^{13} \mathrm{C}$-labeled ribonucleotides. Methods Enzymol. 2000; 317:18-38.

[6] Tolbert TJ, Williamson JR. Preparation of specifically deuterated and ${ }^{13} \mathrm{C}$-labeled RNA for NMR studies using enzymatic synthesis. J Am Chem Soc. 1997;119(50):12100-8. doi:10.1021/ja9725054

[7] Tolbert TJ, Williamson JR. Preparation of specifically deuterated RNA for NMR studies using a combination of chemical and enzymatic synthesis. J Am Chem Soc. 1996;118(34):7929-40. doi:10.1021/ja961274i

[8] Ingle S, Azad RN, Jain SS, Tullius TD. Chemical probing of RNA with the hydroxyl radical at single-atom resolution. Nucleic Acids Res. 2014;42(20):12758-67. doi:10.1093/nar/gku934

[9] Arthur PK, Alvarado LJ, Dayie TK. Expression, purification and analysis of the activity of enzymes from the pentose phosphate pathway. Protein Expr Purif. 2011;76(2):229-37. doi:10.1016/j. pep.2010.11.008

[10] Zhang Y, Kumar S, Fougere M, Carlow CKS. Cofactor-independent phosphoglycerate mutase has an essential role in Caenorhabditis elegans and is conserved in parasitic nematodes. J Biol Chem. 2004;279:37185-90. 
[11] Gross A, Abril O, Lewis JM, Geresh S, Whitesides GM. Practical synthesis of 5-phospho-D-ribosyl alpha-1-pyrophosphate (PRPP): enzymatic routes from ribose 5-phosphate or ribose. J Am Chem Soc. 1983;105(25):7428-35. doi:10.1021/ja003 63a037

[12] Switzer RL, Gibson KJ. Phosphoribosyl pyrophosphate synthetase (ribose-5-phosphate pyrophosphokinase) from Salmonella typhimurium. Methods Enzymol. 1978;51:3-11.

[13] Chander M, Setlow P, Lamani E, Jedrzejas MJ. Structural studies on a 2,3-diphosphoglycerate independent phosphoglycerate mutase from Bacillus stearothermophilus. J Struct Biol. 1999;126(2):156-65. doi:10.1006/jsbi.1999.4112

[14] Anderson PM. CTP synthetase from Escherichia coli: an improved purification procedure and characterization of hysteretic and enzyme concentration effects on kinetic properties. Biochemistry. 1983;22(13):3285-92. doi:10.1021/bi00282a038

[15] Fraser HI, Kvaratskhelia M, White MF. The two analogous phosphoglycerate mutases of Escherichia coli. FEBS Lett. 1999;455(3):344-8. doi:10.1016/S0014-5793(99)00910-2

[16] Sutherland EW, Posternak T, Cori CF. Mechanism of the phosphoglyceric mutase reaction. J Biol Chem. 1949;181:153-9.

[17] Correll CC, Wool IG, Munishkin A. The two faces of the Escherichia coli 23 S rRNA sarcin/ricin domain: the structure at 1.11 Å resolution. J Mol Biol. 1999;292:275-87. doi:10.1006/ jmbi.1999.3072

[18] Correll CC, Munishkin A, Chan YL, Ren Z, Wool IG, Steitz TA. Crystal structure of the ribosomal RNA domain essential for binding elongation factors. Proc Natl Acad Sci USA. 1998;95: 13436-41. doi:10.1073/pnas.95.23.13436

[19] Szewczak AA, Moore PB, Chang YL, Wool IG. The conformation of the sarcin/ricin loop from $28 \mathrm{~S}$ ribosomal RNA. Proc Natl Acad Sci USA. 1993;90:9581-5. doi:10.1073/pnas.90.20.9581
[20] Das R, Laederach A, Pearlman S, Herschlag D, Altman RB. SAFA: semi-automated footprinting analysis software for high-throughput quantification of nucleic acid footprinting experiments. RNA. 2005;11:344-54. doi:10.1261/rna.7214405

\section{COMPETING INTERESTS}

The authors declare no competing interests.

\section{PUBLISHING NOTES}

(C) 2015 Azad et al. This work has been published open access under Creative Commons Attribution License CC BY 4.0, which permits unrestricted use, distribution, and reproduction in any medium, provided the original work is properly cited. Conditions, terms of use and publishing policy can be found at www.scienceopen.com.

Please note that this article may not have been peer reviewed yet and is under continuous post-publication peer review. For the current reviewing status please click here or scan the QR code on the right.

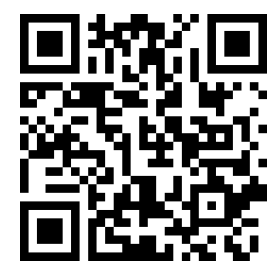

\section{ScienceOPEN.com}

